\title{
The regional heterogeneity of wellbeing "expenditure" preferences: evidence from a simulated allocation choice on the BES indicators ${ }^{\S}$
}

\author{
Leanardo Becchetti, l'Università di Roma Tor Vergata \\ Luisa Corrado, Research Fellow CIMF and CReMlc, Faculty of Economics, \\ University of Cambridge \\ Maurizio Fiaschetti, SOAS University of London
}

\begin{abstract}
With an online survey on major Italian newspapers we ask respondents to simulate the typical policymaker decision, that is, the dilemma of allocating scarce financial resources among alternative competing goals using the domains of the newly defined Italian BES (sustainable and equitable wellbeing) indicators. Our main finding is that homogeneity of choices is rejected since preferred allocations are strongly affected by socio-demographic factors and mainly by political orientation, age, education and gender. An important related result is that education and political orientation significantly affect preferences toward sustainable development. We as well find that respondents' expenditure preferences on a given BES domain are mainly affected by the relative scarcity/abundance of wellbeing on that given domain at the regional level.
\end{abstract}

Keywords: regional wellbeing indicators, political preferences, wellbeing preferences.

JEL numbers: H5 (national government expenditure and related policies); 10 (health education and welfare); HO (public economics); R10 (general regional economics).

\footnotetext{
$\S$ The paper is a part of a research coordinated by Laboratorio RicercAzione from Formazione Quadri Terzo Settore and sponsored by Fondazione con il Sud. The authors thank all the scientific board of FQTS and Fondazione con il SUd for their support, Tommaso Proietti for comments and suggestions, Roberto Porciello and Focusmarketing for their precious coordination and research assistance in bulding the online survey. Finally we thank the newspapers Messaggero, Avvenire and Unità for hosting the survey.
} 


\section{Introduction}

For a long time academics and policymakers explicitly or implicitly considered GDP as a synthetic measure sufficient to capture also the broader concepts of wellbeing and life satisfaction'. Several contributions have recently shown however that the nexus between GDP growth and wellbeing is quite complex. ${ }^{2}$

First, even a variable such as satisfaction in the economic domain (which should be more closely related to GDP than life satisfaction) depends more directly on disposable household income after paying taxes and fundamental public goods such as health and education. As a consequence, since it is not granted that GDP growth and household disposable income move in the same direction for each individual in a given country, GDP and wellbeing may partially diverge. ${ }^{3}$ Second, life satisfaction also depends on "relative income", that is, on comparisons of our economic wellbeing with that of our peers, so that "treadmill effects" and rising inequality may counteract the positive impact of GDP growth on life satisfaction (see, among others, Ferrer-i-Carbonell, 2005; Senik, 2004 and Jiang and Sato, 2009). ${ }^{4}$ Third, household disposable income is neither a necessary nor a sufficient condition to gain access to some goods which contribute significantly to life satisfaction such as common goods, public goods and relational goods. ${ }^{5}$

All these considerations led many to argue that the wealth of nations is not just GDP but the stock of economic, environmental, cultural, relational and spiritual goods which a given community may enjoy. As a consequence, while GDP growth is crucially needed in order to fight unemployment and service the government debt, broader concepts of wellbeing and life satisfaction should be pursued and taken into account as

\footnotetext{
${ }^{1}$ An exception is Buthan where in 1972 a system of surveys was set up in order to measure the population wellbeing through the so called "Gross National Happiness" Index.

${ }^{2}$ For the debate on the relationship between income and happiness see, among others, the opposite views of Easterlin and Angelescu (2009).

${ }^{3}$ A relevant example being Ireland which, in the data of Bartolini et al. (2008) displays one of the largest increases in GDP in the last decade, coupled by one of the lowest changes in life satisfaction among EU countries. One of the factors explaining this finding is that fiscal advantages led companies to set their accounting profits in Ireland, even though the economic value is actually not enjoyed in the same country.
}

${ }^{4}$ More recently Author citation (2013a) show that countries, and not only individuals, may be reference groups documenting that life satisfaction is reduced by higher income in neighbouring countries in proportion to the media exposure of each individual.

5 On the debate on relational goods and their impact on wellbeing see, among others, Gui (2005), Ulhaner (1989) and Bruni and Stanca (2008). For the role of relational goods in explaining the Easterlin paradox see Bartolini et al. (2008). 
well if politicians in charge want to maintain the support of their voters in order to be reelected. ${ }^{6}$ This explains their growing interest on these issues.

An important recommendation to policymakers for the adoption of more articulated wellbeing indicators came from the Sen-Stiglitz commission. ${ }^{7}$ Following this suggestion the Italian National Statistical Institute (henceforth ISTAT) launched in 2011 a threestep process for the creation of an index of equitable and sustainable wellbeing (BES) ${ }^{8}$ starting from consultation with a council of representative members of the different interest groups in the Italian society (CNEL) ${ }^{9}$ In a first step CNEL members were asked to identify what they thought were the most important wellbeing domains. In a second step, ad hoc commissions of experts started their work in each domain in order to determine proper indicators. In a third step the indicators were in turn evaluated and validated again by CNEL members in a second round of consultations which led to the definition of the final composite BES indicator.

This process led to the identification of the following twelve BES domains, each one articulated in a set of subdomains: ${ }^{10}$

1. Health

2. Education and training

3. Work and life balance

4. Economic well-being

5. Social relationship

6. Politics and Institutions

7. Safety

8. Subjective wellbeing

9. Natural and cultural heritage

${ }^{6} \mathrm{~A}$ divergence between per capita GDP growth and life satisfaction trends similar to that observed by Easterlin occurred in the Arab spring countries and the neglect of life satisfaction indicators may be at the root of the limited capacity of political leaders of those countries to understand and prevent social and political unrest. Domestic life satisfaction levels and their differences are currently measured and used to predict migration flows across countries.

7 See Stiglitz et al. (2012).

${ }^{8}$ The BES comes last in a long history of broader wellbeing indexes such as the UNDP Human Development Index, the OECD Better Life Index, the Genuine Progress Indicator, the Ecological Footprint the Happy life Planet index. A critical survey of these indicators is beyond the scope of our paper.

9 CNEL (National Council of Economics and Labour) is a committee of sixty-four councillors whose composition is aimed to mimic the economic and civil heterogeneity of the Country: the members of the Council hold their office for five years and may be reconfirmed. Ten experts are chosen among qualified representatives of the economic, social, and legal fields: eight of these are chosen and nominated by the President of the Republic and two are nominated by the President of the Republic upon the Prime Minister's proposal and the Cabinet's deliberation. Forty-eight members are chosen to represent public and private-sector producers of goods and services with the following composition: twenty-two among the employees, three within the public and private management category, nine among self-employed workers and seventeen are industry representatives. Finally six members are representatives of social service and voluntary organisations and the President of CNEL is an external member of the council.

10 The complete set of 134 specific indicators falling in the 12 domains validated by CNEL members is attached in Appendix $B$ that is available upon request. For additional related information on the BES see the English version of the ISTAT/BES official website http://www. misuredelbenessere.it/index.php?id=48. 
10. Environment

11. Research and innovation

12. Quality of services

The first BES report (2013) providing a snapshot of wellbeing domains and indicators in Italy was officially released on $12^{\text {th }}$ March 2013.

The articulated framework adopted to produce the BES index, though complex, is able to overcome the two opposite critiques to objective and subjective wellbeing indicators advanced by the academic literature. The main critique to objective indicators is about their claimed paternalism; even in the more "enlightened" proposals, it is always a commission of experts which decides what is good for the society (Sugden, 2008). Subjective indicators, though not affected by paternalism, are subject to the Amarthya Sen's "happy slave" critique, as people might be so deprived of their rights not to yearn for a better life. ${ }^{11}$ These "happy slaves" may be willing to accept a low level of aspirations and their life would never improve if political decisions were based on their revealed subjective wellbeing preferences.

The ISTAT process yielding the BES indicators contains elements partially overcoming both critiques. It is non paternalistic since it is the result of a three-step process prompted and eventually delivered by a representative body (i.e. the CNEL) mimicking the heterogeneous composition of the economic and civil society. It overcomes the "happy slave critique" since it dedicates to subjective measures only one domain (n.8 "subjective wellbeing") and uses very few subjective indicators in other domains (see Appendix B). ${ }^{12}$ The BES is also intentionally made of a set of indicators with no attempt to produce a synthetic index which would inevitably raise problems related to its interpretation and aggregation. The final outcome of the BES is, in fact, a list of equally weighted indicators which are assumed to represent wellbeing for all individuals in the country. Though parsimonious and originated by a bottom-up process, the BES retains the traditional problems of composite indicators mainly due to the heterogeneity of their components. In order to have a fair representation of wellbeing, then, it scomponents heterogeneity should be addressed and this is the main aim of our research.

The importance of context in shaping such heterogeneity is a well-known result. ${ }^{13}$ As the most recent literature on heterogeneous wellbeing determinants claims, both the personal and the socio-geographic contexts play a remarkable role in shaping and

11 "The defeated and the downtrodden come to lack the courage to desire things that others more favourably treated by society desire with easy confidence" (Sen, 1985: 15).

12 Note as well that, even though maximising subjective wellbeing is not advisable since subjective indicators depend too much on the heterogeneity of individual expectations, it is crucial to measure such variable since unhappiness may have strong consequences on objective indicators such as health, social capital, political stability etc. On the different measures of subjective wellbeing see, among the others, Helliwell and Barrington-Leigh (2010) and Anand et al. (2011). The appendixes A and B are available upon request.

13 The issue was introduced by Herbert Simon (See Simon, 1956) whose evocative scissors metaphore defined behaviour as the conjunction of the cognition and context blade. See also Clark (2015) for the analysis of behaviour in context. 
affecting wellbeing conditions through psychological (i.e. idiosyncratic) and geographical (i.e. regional) dimensions. ${ }^{14}$ Both dimensions have the same effect on wellbeing measures: they convey heterogeneity in the weights associated to its drivers.

Our research aims primarily to identify such weights addressing two main dimensions of heterogeneity in subjective wellbeing preferences: individual characteristics and contextual attributes. In particular we are interested in addressing whether and how they are affected by individual socio-demographic factors such as political orientation, age, gender, income, education and by (the characteristics of) the geographical area of residence. In this respect, we will assess whether respondents' expenditure preferences on a given BES domain are affected by the relative scarcity/abundance of wellbeing on that given domain at the regional level. One of the main strengths of our research is the direct link to a list of wellbeing indicators not created ad hoc for research purposes, but resulting from a long, participated process and publicly adopted as a benchmark in Italy. An apparent limit may be that such benchmark is country specific. It has to be considered, though, that Italy is the first country to adopt this participated process stemming from the recommendation of the Sen-Stiglitz commission and that other countries may follow in the future. Hence, our empirical findings may (and in fact do) provide relevant policy suggestions for such countries. Furthermore, even if applied to other countries, the process is extremely likely to identify a list of indicators not so different from those considered in this paper. Hence, results on preference weights based on the Italian indicators may provide relevant insights even for countries not adopting such measures at the moment.

The search for proper weights in the aggregation of composite wellbeing indicators is a crucial issue in the literature and our empirical analysis based on a representative sample of respondents proposes a methodology providing such weights as a result of the aggregation of their revealed preferences. In addition our work provides valuable and precious information to policymakers focusing on:

- wellbeing preferences and the socio-demographic factors explaining their heterogeneity;

- the geographical dimension of wellbeing and its distribution across the country;

- the effect of political orientation on between- and within-domain preferences;

\footnotetext{
${ }^{14}$ Among others, see Grubium (2000) and Sointu (2005) for an overview of the contextualist interpretation of wellbeing, Atkinson and Fleuret (2007) for a critical review of the relationship between wellbeing and the geographical context, Kahneman and Krueger (2006) for the development of subjective wellbeing measures and OECD (2014) for the dichotomy in developed/developing countries.
} 
With respect to the last point our aim is to contribute to the extensive literature on retrospecting voting ${ }^{15}$ by providing an in-depth analysis of domains/items affected/not affected by political orientation where the latter are defined as "large coalition items and/or domains". Our claim is that once widely adopted, the BES can help to identify a map of large coalition domains/items to be matched with those of policy makers and their political orientation. The result would be a geography of "easier adoption" policy measures, i.e. those issues for which the probability of reaching an agreement is maximized notwithstanding the potentially different political orientation. Such a result is particularly useful when there is the need of coordinating a centralized decision making process with heterogeneous regional governments and electoral bodies. The European Union is a typical example: the actual policy maker (the EU Commission), though formally relying on a unified elected body (the Parliament), is still deeply influenced by national governments and their heterogeneous constituencies. This might (and in fact did in the past) result in a slow and unsuccessful decision process at the local (national and sub-national) level.

Our contribution is innovative since, by allowing for differentiated weights, it enables a fairer and more effective representation of the heterogeneous wellbeing conditions of the country. It is also innovative since most of the empirical works investigating the determinants of political preferences have focused their attention on specific factors affecting support for a specific wellbeing domain (i.e. environmental sustainability, redistribution etc.), neglecting how the weights on the different domains are distributed. In this respect Oswald and Powdthavee (2010) find that children gender significantly affects political preferences. The authors argue that this depends on the influence that sons and daughters have on their parents and on the impact that gender has on political preferences. Males have been proven to be primarily concerned about lower taxes, while females about the quality of health services (Campbell, 2004). These findings are somewhat consistent with the behavioural economic literature showing that women tend to be more risk averse, less overconfident, more inequity averse and more competitive averse than men in lab experiments (Croson and Gneezy, 2009) and, again, claiming a direct effect of socio-demographic characteristics on behaviour. On the nexus between context and behaviour Kuhn (2011) finds that East Germans are more oriented toward state redistribution and progressive taxation vis-àvis West Germans. As it is well known, differences in redistribution preferences may depend on the perception of vertical mobility and/or the belief that luck, birth, connections and/or corruption determine wealth (Alesina and Angeletos, 2005). Alesina and Glaeser (2004) document that such difference is wider between Americans and Europeans, with the latter declaring in a much higher proportion that the poor have to be blamed. De Silva and Pownall (2012) find that educated females are more

\footnotetext{
15 There is a considerable amount of literature about how citizens use diagnostic information such as macroeconomic or personal conditions to evaluate policy makers achievements, see, among the others, Bélanger et al. (2013) for an updated analysis of the economic perception and voting. Liberini et al. (2014) enhance the analysis introducig a model with (subjective) wellbeing measures. Differently Psycharis et al. (2015) provide a description of the link between politics and the distribution of the regional public investments in Greece.
} 
likely to have green preferences. It is worth noting, though, that all these papers look at just one specific aspect of political preferences (redistribution, environmental concerns) at a time, whereas our paper deals with all the dimensions of wellbeing as defined by the BES indicators.

Our approach contributes to this strand of literature by asking the respondents to simulate the policymaker decision, that is, the dilemma of allocating scarce financial resources among alternative competing goals. A standard result of the contingent evaluation literature is that survey answers may be biased when respondent choices are virtual and do not imply monetary losses/gains for them (Carson et al., 2001). For instance, the risk of manipulation is very high when trying to calculate consumer surplus by asking respondents' willingness to pay for a given product since, in that case, the respondent believes that strategic answering may potentially bring monetary benefits (or avoid costs) to him. In our case the risk of manipulation is much smaller since the respondent has to decide about a virtual government (and not her own) outlay. We therefore expect that the respondent's allocation choice coincides exactly with the message that the latter wants to convey to policymakers, namely with her/his own wellbeing expenditure preferences.

\subsection{The geographic dimension of the BES Domains}

The BES expenditure preferences and the local level policies in a specific wellbeing domain vary greatly in the geographical space because of the characteristics of the regions and localities where respondents live, study and work. In this vein the OECD report "Making Better Policies for Better Lives" (2013) aims at identifying the local social and political drivers of individual well-being. What do people value about their regional conditions? Are regional differences in subjective respondents' preferences on a given BES domain affected by the relative scarcity/abundance of wellbeing on that given domain at the regional level?

There are several reasons why specific characteristics pertaining to a region may influence individual wellbeing expenditure preferences over the various BES domains. Rampichini and D'Andrea (1997) stress that regions are important, since individuals from the same region share common socio-economic, political and cultural environments which contribute, alongside individual characteristics, to well-being. A similar point is made by Schyns (2002) as people will have different access to collective provisions (education, wealth, health care, political climate, etc.) depending on their region. Oswald and Wu (2010), in their recent use of objective measures of well-being as a means of corroborating subjective measures, focus on such geographical factors when analyzing the impact of living in different US states on reported well-being.

Author citation (2012) also find that the inclusion of regional effects is important for understanding the degree to which individual well-being is driven by both personal and 
local factors. In particular, absolute regional factors dominate the effect of an individual's position relative to their region for certain non-economic variables. This aspect is also recognized by various EU policies that focus on correcting wide-ranging subnational disparities at the economic and social level: hence, from a policy perspective regional effects should be considered when developing adequate social and economic policies.

We therefore wish to assess whether regional differences in respondents' preferences on a given BES domain are affected by the relative scarcity/abundance of wellbeing on that given domain at the regional level. We expect that two opposite effects may be at work. On the one side, where the wellbeing factor is relatively scarce its marginal impact on wellbeing and, consequently, respondents' relative preferences for it, should be higher (marginal effectiveness hypothesis). On the other side a relatively abundant wellbeing factor may be the effect of stronger preferences of local population for that wellbeing component and of a sorting mechanism by which people with higher preferences in a specific domain come and match with the relative abundance of wellbeing that domain (sorting/preference hypothesis). Note that the two effects produce opposite sign in the correlation between wellbeing factor and preferences thereby making the observed sign uncertain. Whatever the dominant effect, the original contribution of our work for policymakers is to assess the distribution of respondent preferences at regional level and their correlation with socio-demographic factors.

To this extent, alongside the individual (subjective) wellbeing expenditure preferences over the 11 BES domains, we also consider a set of (objective) BES indicators at regional level for each specific BES domain (see Table 1) to reflect the relative scarcity/abundance of wellbeing on that given domain induced by local level policy. This set up allows us to focus both on individuals and on geographical factors, as people's well-being is shaped by a combination of individual and local characteristics. Italy is the first country to adopt such a process hence the results on preference weights on the Italian indicators may provide relevant insights even for countries which do not adopt them at the moment. Identifying such weights is important in order to evaluate whether and in which direction they are affected by socio-demographic factors such as political orientation, age, gender, income, education and/or (characteristics of) the place of residence such as the values of the (objective) BES indicators for a given geographical area.

The paper is organized in five sections (including introduction and conclusions). In the second section we illustrate a simple benchmark theoretical model which is the background of our analysis and helps to clarify our research framework. In the third section we illustrate the survey design and in the fourth section we present and discuss empirical findings. The fifth section concludes. 


\section{The benchmark model}

The reference for our analysis is a simple theoretical framework where each individual has her/his own expectations on how one euro invested in one of the BES domains may positively affect the domain indicators and how progress in such domains may affect her/his own wellbeing.

More formally, we assume the following utility function defined over the set of the $j=1$, ..., J domains for individual $i$ :

where $W_{i j}$ is the $j$-th wellbeing domain for the individual $i$ and $M_{i j}$ is the amount of the total sum ( $M$ euros) invested in the specific domain (where the same total amount, $M$, is virtually allocated to each respondent).

Any interviewed utility maximizing individual should equalize with her/his allocation choices the marginal utility of investing one euro in each domain.

where the above written marginal utilities are given by the product of the marginal impact of one euro invested in the progress of the domain indicator, and the marginal impact of such progress on her/his own utility, . Unfortunately, it is hard to disentangle these two components.

However, the allocation decision represents in itself a good indication on how voters would like politicians to allocate resources among the different domains and gives the possibility to evaluate how different socio-demographic and contextual factors affect such preferences. As it is obvious, expectations on the marginal impacts of one euro invested in the progress of given domains may not coincide with the effective trade-off in investing resources in different domains (that is, the respondent perception of the contribution of each euro invested to the progress in a given domain may be wrong). Nonetheless, the allocation choices to the domain are signalling the effort they would like politicians to exert in each domain. To make a paradoxical example, a respondent may consider of vital importance health but she/he may have the wrong belief that government expenditure on health is totally ineffective. In such case she/he will respond zero to the amount to be invested in health. Even though being biased by her/ his wrong perception on the effect of government expenditure on health, such response expresses her/his own true preference on how government expenditure should be allocated. This is why we consider more correct to define what we measure wellbeing expenditure preferences and not just wellbeing preferences. Under a more restrictive assumption we may however assume that these wrong perceptions cancel out in the aggregate and therefore wellbeing expenditure preferences grossly coincide with wellbeing preferences as well. 
For some of the BES components, the marginal impact of one euro invested in the progress of the domain indicator can be estimated at the regional level, albeit roughly. For example, the decrease in crime associated with an extra euro spent on law enforcement may be a good proxy for the marginal return to a euro spent on the safety component of the BES. ${ }^{16}$

Since we have several regional indicators for each BES domain we derive a composite index as a proxy for the marginal impact of one euro invested in the progress of the domain indicator. Note that our regional BES indicators are collected in 2012 while the individual BES wellbeing expenditure preferences refer to 2013.

In order to match properly our wellbeing indicators with information on wellbeing expenditure preferences recorded at aggregate BES domain level we aggregate the regional indicators in each domain listed in Table 1 . More specifically, we define the composite BES index for the $j$-th domain in the $r$-th region:

as the average of the z-scores of the regional BES indicators for the $j$-th domain in the $r$-th region. ${ }^{17}$ The aggregation requires that for each $j$-th domain all the BES indicators are normalised, i.e., all indicators are on the same scale in order to avoid distortions due to variables with large values or variances. Since the indicators use different scales of normalization is necessary to remove the scale effects of different measurement units. For this reason we convert all the BES indicators into z-scores that are obtained by subtracting the mean from the observation and dividing the result by the standard deviation of the variable. For indicators in which high values correspond to low levels of that specific BES domain, we reverse the order by subtracting the observation from the mean and dividing the result by the standard deviation. In other words for indicator such as "share of over-qualified employees" in the work and life balance domain we use the conventional z-score, whereas for indicators such as "work accidents" we produce a z-score in which higher percentage of work accidents correspond to lower levels in the work and life balance domain.

Figure 1 shows the map of the regional BES composite indices. There is indication that certain macroeconomic areas are relatively more abundant/scarce in a given domain. For example, regions in the North display a higher level of economic well-being, work and life balance, health, research and innovation and quality of services. The econometric analysis that follows will tell us whether the relative abundance of the

\footnotetext{
${ }^{16}$ An alternative route would be to use public expenditure in each domain. However, inefficiencies and waste in public spending would lead to overestimate the marginal return of an extra euro spent in each domain.

17 We follow the aggregation method implemented in the construction of similar composite indicators. See, for example, the aggregation method to build the Environmental Sustainability Index (2005 Environmental Sustainability Index Benchmarking Environmental Stewardship, Appendix A Methodology) available at http://sedac.ciesin.columbia.edu/data/set/esi-environmental-sustainability-index-2005/ data-download.
} 
wellbeing indicator at regional level is correlated with lower (higher) wellbeing expenditure preferences according to the marginal effectiveness (sorting/preference) hypothesis.

Based on our theoretical framework our research may contribute originally to the literature in four respects. First, we can test how much the assumption of homogeneous weights in wellbeing domains (typical of representative consumer models, or implicit in the use of composite wellbeing indicators at national level) sacrifices about the knowledge of individual preferences. With our data and theoretical framework the hypothesis that the weights are the same for each individual or sociodemographic group may be directly tested and accepted or rejected. Second, our empirical findings may provide precious information to policymakers and social scientists about which drivers affect (and which do not) heterogeneity in invidual preference weights according to the differential impact of one euro invested in the progress of the domain indicator. Third, by using the regional BES indicators as controls, we may test how relative abundance/scarcity of wellbeing in the specific domain at local level affects wellbeing expenditure preferences thus making a specific case for the need of regional policies. Fourth, we propose a methodology which can be used to calculate preference weights as a result of the aggregation of revealed preferences of representative samples of respondents.

A final remark is that, as documented in the previous section, the list of domains and the set of indicators created by groups of experts for each domain contain a few purely subjective elements (i.e. subjective wellbeing among domains and, as an example, job satisfaction among indicators in specific domains). Since subjective domains are too general and make unclear what it means investing economic resources to improve them we exclude them from our empirical analysis (i.e. the $8^{\text {th }}$ domain of subjective wellbeing is excluded).

\section{The research design}

Our empirical analysis is based on data collected with an online survey where respondents are asked to allocate the hypothetical sum of 100 million euros to promote wellbeing improvement in one of the 11 considered BES domains (see the attached questionnaire in the Appendix A). The sub-questions which follow ask respondents to identify, within each domain, the first five priorities (ranked in ascending order) among the indicators included in that domain. ${ }^{18}$ The questionnaire also collects data on

\footnotetext{
18 Note that the survey question changes when we ask preferences about subdomain specific indicators (from the simulation of an invested sum to a more general indication of priorities). This is because some of these indicators are subjective and it is not clear whether other of them may be affected by government expenditure (see Appendix B).
} 
standard socio-demographic variables and the database is enriched with data on characteristics of the province/region in which the respondent lives including values of BES indicators at that level in order to provide the contextual framework.

The survey has been launched on the websites of three main Italian newspapers on March 2013. The first, Messaggero, is the fifth most read Italian newspaper (excluding sport newspapers) with a reputation of being at the center-right of political orientation. The second, Avvenire, is the main Italian catholic newspaper. Its readers reflect the ideological divide of Italian believers since they are balanced between right and left wing orientation. The third, l'Unità, is more left wing oriented being the official newspaper of the Democrat Party. Beyond these three major newspapers which accepted to participate to our research, the online survey appeared as well on several minor newspapers and websites whose list is reported in the footnote below. ${ }^{19}$

The online questionnaire has a control check which prevents respondents from filling the form more than once from the same web address. At end of July, after five months from the start of the online survey we collected 2,605 complete questionnaires. An inevitable bias of our survey is that the sample of respondents is not representative of the Italian population and biased toward those who use the web who tend to be relatively younger and more educated.

\subsection{Weighting Our Sample}

Table 2 provides a comparison of the characteristics of survey respondents with those of the national population. We use demographic information from the Italian Office for National Statistics (ISTAT) ${ }^{20}$ to create population weights in order to correct for the biasedness of the survey sample (which is not sampled at random).

As Table 2 shows there is a substantial bias (as it is expected to be in online surveys) in particular in terms of gender, age, education and regional location of the surveyed respondents. More specifically, our sample under represents males (women account for 55.5 percent of the sample), respondents with a primary/middle school degree $(0.31$ and 6.56 percent against 20.10 and 29.77 percent respectively in the national population) and over represents respondents aged 25-34, 35-44 and 45-54 (22, 22.65 and 24.61 percent against $11.87,15.75$ and 15.01 percent respectively in the national population). In the sample 57.7 percent of respondents have at least a University degree against 10.80 percent in the national population. These findings confirm that the community of internet users who respond to our survey is imbalanced toward highly

19 These are Forum Nazionale Terzo Settore, FQTS, ARCI, ConVol, CSV Net, Labsus, Dignità del lavoro, Auser, Avis, Anpas, Bandiera Gialla, La perfetta letizia, Mondo alla Rovescia, Confini online, Il Metapontino.it, ARCI, Campania, Blog vitobiolchini, Domos (domotica sociale).

\footnotetext{
${ }^{20}$ Italian National Institute of Statistics ISTAT $15^{\circ}$ Censimento della Popolazione e delle Abitazioni 2011. http://www.istat.it/it/censimento-popolazione/censimento-popolazione-2011. The italian population Census takes place every 10 years.
} 
educated and middle aged individuals. Concerning geographic location all regions are either over or under-represented (except Basilicata, Marche, Liguria, Marche, Puglia, Piemonte and Valle D'Aosta and Calabria).

We use sampling weights to account for these design-based inequalities. Specifically, we use a raking ratio estimation (Deming 1943, Kalton 1983, Izrael at al. 2009) that adjusts the sampling weights of the cases in the sample so that the marginal totals of the adjusted weights on the specified characteristics (gender, age, education and geographic location) match the corresponding totals for the national population. The actual algorithm involves repeatedly estimating weights across each set of variables in turn until the weights converge and stop changing. Essentially, raking forces the survey totals to match the known population totals by assigning a weight to each respondent. We also use a weight trimming method ${ }^{21}$ implemented during the last step of the raking iterative process in order to ensure that: i) limits are placed on low and high weight values in the final weights, ii) the convergence criteria are satisfied, and the weights sum to the population total. Weight trimming increases the value of extremely low weights and decreases the value of extremely high weight values to reduce their impact on the variance of the estimates. For example, all the weights that are less than 0.2 are increased to 0.2 , and all the weights that are greater than 5 are reduced to 5. That is we truncate weights above the 95-th percentile and below the 5th percentile and trim that weight by making it equal to the limit. The objective of weight trimming method is to reduce the mean squared error (MSE) of the outcome estimates. It is worth noting that the main findings that follow are not substantially different when we use the unweighted sample or the sample weighted on the characteristics of the subpopulation reading online journals. Results are partially available in a former version of this paper, omitted here for reasons of space and available upon request.

\section{Statistical findings}

In Table 3 we summarize descriptive statistics on the variables used for our empirical analysis. Note that in the case of the economic wellbeing, politics and institutions, security, education, work and life balance, health and quality of services domains the maximum is 100 , that is, for each of the four domains at least one respondent allocates all her/his virtual sum in them. For all domains the minimum is zero implying that there is at least one respondent investing no money in them. Looking at other variables

\footnotetext{
${ }^{21}$ We use the command ipfweight in Stata to implement the trimming method during the raking iterative process.
} 
gender is quite balanced average political orientation is slightly left wing biased $(-2.70)^{22}$ and 56 percent of them are married or cohabiting.

Descriptive evidence from Figure 2 documents that the BES domain for which the Italians are willing to pay more is the health domain. According to our findings, sample respondents would allocate on average 17.4 percent of their virtual sum on it. The health domain is followed by education and training (12.8 percent) and by work and life balance (around 10.7 percent). All the other domains are between 8.9 (economic wellbeing) and 6.6 percent (safety), with the exception of politics and institutions where we fall to 3.8 percent. ${ }^{23}$

The five socio-demographic discriminants we expect may affect preference weights are left/right wing political orientation, gender, education, income and North/South geographical location.

As Figure 3 shows we start by inspecting the contribution of the political orientation variable. From a descriptive point of view we look at average weights and 95 percent confidence intervals for the adjoining sets of those with positive (right wing), vis-à-vis those with negative (left wing) variable values. In spite of our split criteria which do not enhance the left/right divide (we could have taken top and bottom terciles to rule out an intermediate moderate group and enhance dissimilarities between the two selected subgroups) we find many significant differences.

The most remarkable difference is in the health domain where the right wing group allocates 17.99 percent of the sum against 16.99 percent of the left wing group. The difference among subgroup means is significant under the normal distribution assumption since the two $95 \%$ confidence intervals do not overlap. The difference on economic wellbeing is similarly high $(9.65$ percent of the money allocated by the right wing group against 8.39 percent by the left wing group) and statistically significant. The difference on security is smaller (7.34 percent of the money allocated by the right wing group against 6.08 percent by the left wing group), but still statistically significant. The left wing group also allocates significantly more in the education (13.32 against 12.22 percent), in the environment ( 8.84 against 8.03 percent), in the research and innovation (8.94 against 8.31 percent) and in social relationships (7.22 against 6.56 percent) domains. "Large coalition domains" in which we do not register significant differences between the two political orientations are work and life balance, quality of services, and natural and cultural heritage. Based on these findings, in a hypothetic trade-off between economic growth and environmental sustainability left wing orientation seems much more supportive of sustainable

\footnotetext{
22 The political orientation variable classifies respondents in a range going from -10 (extreme left) to +10 (extreme right). The question actually asks respondents to locate themselves on a range going from 0 to 10 at the right and 0 to 10 at the left to avoid association between minus/plus signs and a given political orientation. We however recode the variable giving a negative sign to values at the left of the zero for obvious reasons of monotonicity of the political orientation variable.
}

${ }^{23}$ This first descriptive evidence is consistent with a preliminary descriptive inquiry run by ISTAT (2012) on BES preferences. 
wellbeing claims, given its relatively stronger orientation for the environment and natural and cultural heritage and its relatively lower orientation for the economic wellbeing domain.

What appears noteworthy is that, if we take into account the second potential discriminant (gender), we find significant differences between males and females in only three of the BES domains. Females allocate more in health (17.93 percent against 16.91 of males) and economic wellbeing (9.54 percent against 8.33 ), whereas males allocate more in education (13.62 percent against 12.08). The same occurs for the third discriminant (income by comparing those below 30,000 euros and those above 30.000 euros) where three domains show some differences. As expected, low income allocate more in economic wellbeing (9.59 percent against 7.47), whereas top earners show a higher preference for work and life balance (11.14 percent against 10.50) and for social relationships (7.24 against 6.24 percent). Along this line and geographic location shows even weaker differences. ${ }^{24}$

In order to investigate the role of the fourth potential discriminant (education) we compare respondents with a university degree with those who have less than a high school qualification. The differences are in this case relevant. The low education group allocates significantly more on health (17.82 against 15.27 percent) and economic wellbeing (9.22 against 7.43 percent), while significantly less on education and training (12.75 against 13.36 percent), social relationships (6.67 against 8.40 percent), natural and cultural heritage ( 7.40 against 8.33 percent), environment ( 8.35 against 9.22 percent) and research and innovation ( 8.61 against 8.98 percent). It seems that this group suffers from a relatively lower economic wellbeing which forces its members to rely more on public health, be less environmentally sensitive in a hypothetical trade-off between economic growth and environmental sustainability. In spite of its lower education level, the group allocates relatively less resources to education and training and to research and innovation (which is myopic and contradictory if we believe to a positive contribution of these two variables to economic wellbeing). Note that some of these differences (notably those on health and education and training) remain significant if we narrow distances between the two subgroups by comparing those with a university degree with a complementary group which includes also respondents who achieved a high school degree.

Last but not least, age discriminates on three domains when we compare those over 50es with those below 40es. A first difference is that the elders want to invest more in education (13.21 against 12.47 percent), work and life balance (11.17 against 10.21 percent) and, as expected, in health (17.80 against 17.05 percent). Conversely the younger want to invest more in economic wellbeing and social relationships (respectively 10.12 against 7.79 percent and 7.34 against 6.54 ).

\footnotetext{
24 Differences among subgroup means for the four Italian macroareas (North East, North West, Centre and South) are not significant as well. They are omitted for reasons of space and available upon request.
} 
Our final remarks are that, at least when we consider descriptive evidence on major domains, only three of the five potential discriminants matter (left/right wing political orientation, education and age). More specifically, highly educated and left wing oriented respondents result to be more inclined toward environmental sustainability, defense of the cultural heritage, research and innovation and education, while right wing oriented respondents toward security and economic wellbeing. Domains on which all respondents have similar preferences are quality of services, politics and institutions, work and life balance and social relationships.

\subsection{The Geographic Dimension of BES Domains.}

The maps of the BES domains reported in Figure 4 show a high regional variability indicating that where people live matters for well-being. A higher geographic variability in the expenditure allocation to the various BES domains may, indeed, reflect the fact that the outcomes in each dimensions vary greatly between regions because of the characteristics of the regions and localities where respondents live, study and work including the relative scarcity/abundance of that specific domain. ${ }^{25}$ Comparing the objective and subjective BES measures in Figures 1 and 4 we can see that the impact of the relative scarcity/abundance of the specific BES indicators at the regional level are mixed when examined at descriptive level. In some cases the scarcity effect prevails, i.e. where the domain is scarce the marginal effectiveness of each additional euro spent is higher and people would like to invest relatively more in that specific domain. In other cases the opposite occurs and a higher wellbeing expenditure preference for a certain domain is associated to its relative abundance.

Geographic clustering generated by sorting/preference effects reflects the fact that many of the policies that influence most directly people's live are local or regional; this generates endogeneity between the individual regressors and the unobserved effects at the local level (Benabou, 1996). Such choice involves information that is in part unobservable, and therefore requires making inferences among the possible factors which contribute to the outcome (Moffitt, 2001). We assume as well that individual preferences on the BES domain depend on the characteristics of the region and locality (province) where each individual lives (see also Author citation, 2012). Specifically, we assume that individuals decide where to live on the basis of certain characteristics of the area represented by its social, institutional and economic environment and by place-based policy actions affecting the regional endowment of the various wellbeing domains that respond to their specific expectations (Author citation, 2013b). Ultimately, the characteristics of the area chosen affect the subjective allocation over

25 This is broadly confirmed by the analysis of variance where the unobserved variation between regions accounts for a larger proportion of the overall variation in the (subjective) wellbeing expenditure preferences over the 11 BES domains. The ANOVA results are available upon request. 
the BES domains. As the BES domains are a mix of both material and non material conditions we look at how they are influenced by local characteristics to provide direct information on well-being distribution in the population and across places within a country.

We formalise this notion and consider that the dependent variable related to the $j$-th BES domain for the $i$-th individual living in the $r$-th region and $p$-th province, $B E S_{i j, p r}$, depends on a set of inidividual controls, $X_{i, p r}$, and by an unobservable quality effect, $\eta_{j, p r}$, that reflects the attractiveness of locality $p$ within region $r$ for the specific $j$-th domain. We assume that the attractiveness of a locality depends on its specific observable attributes, $Z_{p}$, on the observable attributes of the region, $Z_{r}$, on the (objective) BES composite indicators at the regional level for the $j$-th BES domain, , and on an unobservable component, $u_{j, p r}$, which is normally distributed:

$$
\begin{aligned}
& B E S_{, p r}=X_{i, p r} \beta_{j}+\varepsilon_{i j, p r}+\eta_{j, p r} \\
& \eta_{j, p}=Z \beta Z_{p} \mathbb{\beta}_{j} \pm_{r} B_{,}, \mathbb{K}_{r}{ }_{r} S_{j, p} \iota
\end{aligned}
$$

$$
E\left(u_{j, p r}\right)=0 \quad \operatorname{Var}\left(u_{j, p r}\right)=\sigma_{u}^{2}
$$

The two set of variables $Z_{r}$ and $Z_{p}$ enter model (1) with coefficients $B_{j p}$ and $B_{j r}$, respectively, while the regional BES indicators, , enter the model with coeffcient $a_{j r}$.

Given that regional clustering generated by sorting/preference effects generally induces correlation between the observed individual attributes, $\mathrm{X}_{i, p r}$, and the unobserved attributes at the local level, $\eta_{j, p r}$, we follow Mundlak (1978) and assume that the unobservable effects, $\eta_{j, p r}$, are normally distributed, conditional on contextual effects at the regional, $Z_{r}$, and local level effects, $Z_{p}$, which account for clustering of individuals into groups associated with groups' unobserved characteristics (see also Bayer and Ross, 2006). ${ }^{26}$ Among the set of contextual effects we also consider the set of (objective) BES indicators at the regional level for each specific BES domain to reflect sorting/preferences effects generated by the relative scarcity/abundance of wellbeing on that given domain induced by regional level policy.

\footnotetext{
${ }^{26}$ In model (1) $Z_{r}$ and $Z_{p}$ denote the set of contextual effects at the regional and local level such as regional per capita GDP, the share of provincial population with no more than middle school degree and the percent of senate voters at regional level (Author citation, 2015).
} 


\subsection{Econometric findings: OLS estimates}

We check whether tendencies observed in descriptive statistics, and tests on the differences of subgroup means, are confirmed in econometric estimates where we control for the concurring effects of age and income classes, civil, family and work status, industry dummies, web source of survey compilation and other characteristics of the place of residence.

Our first econometric approximation is the following baseline OLS model ${ }^{27}$

where the dependent variable (BES) is the share invested by subject $i$ in the $j$-th BES domain, RightWing is the respondent's political orientation expressed (as explained above) on a $-10 /+10$ scale $(-10$ extreme left, +10 extreme right), Bachelor is a $(0 / 1)$ dummy for those having a university degree or above, Low/MiddleEdu is a dummy for those having no more than Middle School degree (High School is the omitted benchmark), Female is a $(0 / 1)$ gender dummy taking value one if the respondent is of female gender and zero otherwise. The specification includes a geographic dummy (Macroregion), the observation coming from the North-East, North-West or South and Islands macro regions of Italy as defined from the National Statistical Institute categories. Age is controlled for with a set of age class dummies picking up five-year age intervals starting from 25-30 and ending up with 75-80. Under 25 and Over 80 are two end-classes also included as age dummies in the estimate, while the 30-35 age class is the omitted benchmark. DIncomeClass are five income dummies which pick up income classes as included in the questionnaire (the class between 15,000 and 30,000 euros per year is the omitted benchmark). MaritalStatus dummies pick up the Divorced, Single, Separate and Widowed conditions (Married/Cohabitant being the omitted benchmark), Familystatus dummies pick up the following family status conditions (Living Alone, Living with my Original Family, Living with my Partner without Children, Single Parent) with Living with my Partner with Children being the omitted benchmark, JobStatus dummies pick up the following conditions (Fixed Term Contract, Seasonal Contract, Self/Employed, Not Working/Unemployed/Looking for a Job, Redundancy Fund Benefits, Redundancy Worker, Housewife, Student, Retired), OpenEnded contract being the omitted benchmark. Industry dummies pick up the industry in which the respondent works (Agriculture, Manufacturing, Personal Services) with

\footnotetext{
${ }^{27}$ The OLS estimation uses the sampling weights derived in section 3.1.
} 
Tertiary being the omitted benchmark. Dsource are three dummies picking up characteristics of respondents who filled the questionnaires on the websites of the three main newspapers involved (Avvenire, Unità, Messaggero) and are presumably readers of those journals. The omitted benchmark is represented by those who filled the questionnaire from other websites. The inclusion of the Dsource variables is important, especially for the Avvenire newspaper since it may capture religious (beyond political) orientation in our econometric estimates.

Last but not least, we include two types of contextual variables. First, we add three proxies of local economic development, human capital and social capital such as regional per capita GDP28 (GDP), the share of provincial population with no more than middle school degree (MiddleSchool) and the percent of senate voters at regional level (SenateVoters). Second, we include the composite BES index for the $j$-th domain in the $r$-th region (). In equation (1) the subscript $p$ denotes provinces and the subscript $r$ denotes regions. This last set of regressors is important to check whether respondent preferences on a given BES domain are affected by the relative scarcity/abundance of wellbeing on that given domain as measured by the regional composite BES indicators. From a theoretical point of view the expected sign is not clear. There are equal reasons to expect that the relative quality of wellbeing indicators at local level should produce a negative sign (for decreasing marginal utility) or a positive sign when such quality reflects a higher weight of local preferences on that specific domain which actually created consensus for more political effort on the given indicator. Note that the endogeneity between our dependent variable measuring subjective well-being expenditure preferences on the various BES domains and the set of (objective) regional BES indicators is ruled out since our regional contextual controls are collected in the year preceding the survey. Last, is an idiosyncratic error. In all estimates, errors are clustered at province level. In the estimation we use the population weights described in section 3.1 .

Econometric estimates reported in Table 4 confirm the results from descriptive findings and subgroup mean differences commented in the previous section. Right-left wing orientation remains a strongly significant driver of allocation choices. We recall that individuals have been asked to place themselves on an algebraic segment of integers reclassified from -10 (extreme left) to +10 (extreme right). From an economic point of view we find that one integer shift toward right from average political orientation $(-2.7$ in our sample) leads to an increase of 270,000 euros investment in the economic wellbeing domain (out of the 100 million euros to allocate).

Political opinions matter also in other domains. The effect of one integer move to the right (from sample mean political orientation) leads to a reduction in investment of 110,000 euros in the social relations domain, an increase of 160,000 euros in the security domain, a reduction of investment of 100,000 euros in the natural and cultural heritage and a reduction of 140,000 euros in the environment domain. Overall,

${ }^{28} \mathrm{It}$ is measured in thousands of euros. 
econometric findings confirm that the significant differences observed with simple subgroup means in Figures $3 a-3 f$ are robust to the inclusion of all the controls we introduce in the econometric estimates.

To sum up, respondents who classify themselves as right wing invest significantly less in social relations, politics and institutions, environment and natural and cultural heritage and significantly more in safety and economic wellbeing. The other factor we found as having a deep impact on welfare preferences in subgroup mean comparisons was education. In econometric findings graduate respondents invest 1,520,000 euros more on social relations vis-à-vis the high school benchmark. Note as well that respondents with a middle school degree invest significantly less in research and innovation (minus 1,790,000 euros). Note, also, that graduated respondents have a more leftist political orientation (-3.10 against -2.14 of the complementary group). ${ }^{29}$

Among other controls those filling the questionnaire from the Avvenire website invest significantly more in natural and cultural heritage $(1,070,000)$. This finding presumably indicates that religious beliefs, net of political orientation, affect preferences in this domain. Respondents filling the questionnaire from the Messaggero website (right wing) invest significantly more in education $(5,700,000)$ and less in social relations $(-3,190,000)$. Finally, readers of Unità (left wing) are more concerned about investing in politics and institutions $(1,630,000)$ and less in health $(5,810,000)$. The lack of significance of the female dummy is confirmed in all considered domains.

\subsection{Econometric findings: Tobit system estimates}

In order to evaluate the robustness of our findings we must consider at least two specific characteristics of our dependent variables. First, they are left and right censored given the 0 and 100 limit values they can achieve. More specifically on this point, individuals may have liked to go beyond the limits imposed by our questions (the 0-100 percent choice range) by actually "going short" and disinvesting resources from a domain in which they may believe that the government is overinvesting. As well, they may have decided to use some of the disinvested resources to increase above 100 percent investment in domains which they regard as essential. Second, choices on the different domains are correlated with each other since the decision to allocate one euro more in one of them implies that one euro has to be "disinvested" from the others.

We tackle both problems by estimating (1) with a system Tobit specification ${ }^{30}$ where standard errors are clustered at the province level. Using a left censored limit of zero

\footnotetext{
${ }^{29}$ Additional statistics available on request.

30 The Tobit estimation uses the sampling weights derived in section 3.1.
} 
and a right censored limit of 100 a multivariate Tobit model of the $J$ BES domains can be expressed as

where are multivariate normally distributed error terms with zero mean, variance , correlation, and covariance matrix

Given that choices on the different domains are correlated with each other, and assuming a covariance matrix for the error terms given by, we use a Seemingly Unrelated Estimation approach to estimate the (co)variance matrix of the multivariate normal distribution of the estimators for the system of Tobit equations. ${ }^{31}$ In the estimation we use the population weights described in section 3.1.

When comparing OLS and system Tobit estimates, reported in Table 5, we find that the statistical significance is generally similar while magnitudes tend to be larger with the second estimation approach. The rationale is that Tobit estimates consider that border decisions (such as those of investing 0 or all the sum in a single domain) may actually be a lower bound of the true decisions, would the implicit constraint of limiting the choice in the 0-100 percent interval be removed (i.e. allowing respondents to disinvest resources from a domain which they regard as overinvested to invest more than the total in a domain which they regard as underinvested). Our main finding confirms that homogeneity of choices is rejected since preferred allocations are strongly affected by socio-demographic factors and mainly by political orientation, age, education and gender. An important related result is that education and political orientation significantly affect preferences toward sustainable development.

\footnotetext{
31 To estimate the system of Tobit equation we use the SUEST command in STATA. SUEST combines the estimation results -parameter estimates and associated (co)variance matrices- into one parameter vector and simultaneous (co)variance matrix for of the sandwich/robust type. This (co)variance matrix is appropriate even if the estimates were obtained on the same or on overlapping data.
} 
More specifically, with regard to our new estimates, we find that the effect of oneinteger move to the right of political orientation reduces investment in education and training from $-100,000$ to $-110,000$ in social relations from $-110,000$ to $-140,000$ and in natural and cultural heritage from $-100,000$ to $-110,000$. While a more right wing orientation increases investment preferences in economic wellbeing from 270,000 to 320,00 euros and in security from 160,000 to 180,000 . Large coalition domains where political orientation does not matter are those of Work and Life Balance, Quality of Services, Research and Innovation.

Gender is now significantly affecting well-being expenditure preferences. Females would like to invest more in economic well-being $(1,540,000)$ and less in education $(-1,220,000)$ and work and life balance $(-1,240,000)$.

Keeping into account the censored structure of our data increases also substantially magnitudes of the effect of a University degree over the high school omitted benchmark of the sample. The effect on investment is now 1,810,000 euros in the social relations domain and 1,350,000 euros less on health. People with a middle school degree would like to invest relatively more in the health domain $(2,080,000$ euros) and less in education (-1,600,000 euros), in environment security $(-810,000)$, in natural and cultural heritage $(-1,160,000)$ and innovation $(-2,370,000)$.

In the new estimates those filling the questionnaire from the Avvenire website are still investing significantly more in natural and cultural heritage $(1,280,000)$ and respondents filling the questionnaire from the Messaggero website (right wing) significantly more in education $(6,010,000)$ and less in social relations $(-4,180,000)$. Finally, the new results confirm that readers of Unità (left wing) are more concerned about investing in politics and institutions $(2,300,000)$ and less in health $(5,730,000)$.

With respect to the common controls regional GDP is positively correlated with the propensity to invest in education and inversely related with the propensity to invest in health and natural and cultural heritage. The share of people with education up to the middle school correlates positively with the propensity to invest in education and research and innovation and negatively with the propensity to invest in social relations and health. Finally political participation at the regional level (percentage of voters at the senate elections) correlates positively with the propensity to invest in economic well-being and work and life balance and negatively with education.

\subsubsection{Expenditure Preferences and BES Regional Endowment}

We now assess whether regional differences in respondents' preferences on a given BES domain are affected by the relative scarcity/abundance of wellbeing on that given domain at the regional level. 
Based on our considerations formulated in section 2 we consider what follows

i) If the relative abundance of the wellbeing factor at regional level has a positive and significant effect on wellbeing expenditure preferences the "preference/sorting" hypothesis applies.

ii) If the relative abundance of the wellbeing factor at regional level has a negative and significant effect on wellbeing expenditure preferences the "marginal effectiveness" story applies.

To discriminate between i) and ii) we use the composite BES index () described in section 2.

Our findings from the modified specification document the significance of the synthetic indicators. More specifically, in five out of seven cases the "marginal effectiveness" hypothesis applies since respondents are willing to invest more resources, the lower the quality of the aggregate indicator of the BES domain. The five domains where the "marginal effectiveness" dominates are education, work and life balance, economic well-being, environment and security. The two domains where the result is reversed (and the preference/sorting hypothesis applies) are health and natural and cultural heritage.

While natural and cultural heritage is a typical domain where preferences may apply, it may less intuitive why the same reasoning works for the Health domain. It must be however considered that the quality of health in the Italian regions is very polarized with high quality in the North and low quality and widespread episodes of corruption in the South. What may happen is that respondents in regions with low quality of health infrastructure are inclined to believe that the marginal utility of investing in health in their regions is very low and just fueling corruption.

\subsection{Subdomain findings}

As it is clear from the list of BES indicators, not all of them are suitable for improvement with more public expenditure. This is why our type of sub-domain question changes and concerns a scale of priorities and not a simulated investment. Our dependent variable has fixed outcomes that are rank orderable (with values from 1 up to 5 or 0 when the indicator is not ranked among the first five). In addition to it, ordering choices within each domain are correlated for each individual (if the respondent decides to rank one indicator first the other indicators in the domain cannot be first). 
Given these characteristics the best option to tackle our subdomain research question is the rank ordered logit (Beggs et al., 1981) applied in many fields such as voter preferences (Koop and Poirier, 1994), school choice (Mark et al., 2004), marketing (Ahn et al., 2006), demand for classical music (Van Ophem et al., 1999) and transportation studies (Kockelman et al., 2006; Calfee et al., 2001) among others. As is well known however the rank ordered logit approach is feasible when having variables varying not only at individual level (socio-demographic variables) but also at the alternative level (that is, characteristics of the subdomain). Unfortunately our variables do not vary at the alternative level. Since a ranked ordered logit model with no variables varying at subdomain level collapses to a multinomial logit model (Allison and Cristakis, 1994) we opt for this "second best" option.

More in detail, we specify the following multinomial logit model within the $j$-th domain to estimate the probability that the $s_{j}$-th subdomain,, is ranked first:

where $S_{j}$ is the reference subdomain ${ }^{32}$ and the probability distribution of the individual response, , is multinomial with $S_{j-1}-1$ equations. The control variables and the related notation are already described in section 4.3. The suffixes $r$ and $p$ denote, respectively, the region and province where the $i$-th respondent lives. In the estimation we use the population weights described in section 3.1.

In order to know more about the effect of left/wing political orientation on preference heterogeneity, in Table 6 we summarize the results from within-domain effects by identifying the priority item in each domain on which political orientation has a significant impact. 33

Subdomain findings are necessarily different from econometric findings on wellbeing expenditure preferences since they measure within- and not between-domain effects. That is, the fact that there are no significant items in the security domain is perfectly consistent with the significantly higher wellbeing expenditure preferences of right wing respondents for the security domain. It implies however that within that domain there is no significant divergence between left and right respondents about the within domain ranking of priorities for the different security items. Table 6 shows that right wing oriented respondents prioritize relatively more some subdomains in health, economic wellbeing, education, research and innovation and the quality of services. More specifically, they are relatively more concerned about reducing traffic accidents

\footnotetext{
32 We use the largest subdomain as reference. In the multinomial logit model a change in the reference subdomanin does not change the sign of the the marginal effects (Wooldridge, 2002 p. 497-498).

33 We calculate the average marginal effects of a of one-integer move to the right of political orientation on the probability to a specific subdomain is ranked first. Errors are clustered by individual since the ordering of choices within each domain are correlated. Full evidence of multinomial logit estimates according to political orientation is collected in an online appendix available upon request.
} 
and dependencies (sedentarity), increasing per capita net wealth, increasing literacy, promoting accessibility to basic services and prioritizing productive specialization in knowledge intensive sectors. Conversely, left wing oriented respondents prioritise relatively more some subdomains in health, social relations, politics and institutions and the quality of services. Specifically, they prioritise fighting against cancer mortality, funding of associations, supporting participation of women in decisionmaking bodies and in board of directors and are interested in reducing prison density. In a comparative perspective it worth noting that in the Social Relations domain left wing respondents prioritise relative more a socially structured aspect (funding of associations), while right wing respondents an individual aspect (providing free and voluntary help) of it.

If we look at anecdotal evidence on declarations of Italian policymakers we find the overall results of the analysis broadly consistent with our between and within findings. Between-domain findings (Tables 4 and 5) are consistent with right wing politician declarations minimizing the importance of culture and education ${ }^{34}$ and declare themselves very concerned about safety problems (the Lega organized voluntary groups of citizens patrolling cities in the night ("ronde") in the last years in some municipalities of the North). The strategy of enhancing the perception of insecurity of right wing media in the last elections has been acknowledged ex post as one of the most successful. Care for the environment is, on the other hand, typically considered a left issue in Italy (and the Green party which actually did not have much success was clearly identified and placed itself at the left of the political spectrum). Looking at within domain findings (Table 6) care for gender issues both in the workplace and in politics and for the quality of certain public services (i.e. reducing prison density which is part of the political propaganda of the Radical Party) are, on the other hand, typically considered a left issue in Italy. While increasing per capita net wealth and prioritising productive specialization in knowledge intensive sectors are typically associated with growth enhancing policies proposed by right wing politicians.

\section{Conclusions}

The original contribution of our paper to the wellbeing literature hinges upon the analysis of the heterogeneity of individual wellbeing expenditure preferences and on the expenditure trade-offs among different wellbeing domains. More specifically, respondents to an online survey are asked to simulate the policymaker dilemma of allocating a limited sum among alternative policies aimed at increasing wellbeing in different domains. Our reference is a wellbeing indicator, the BES (Sustainable and Equitable Wellbeing) indicator, recently created and adopted as a benchmark in Italy by the National Statistical Institute (ISTAT), with the cooperation of a coalition of

\footnotetext{
${ }^{34}$ On November $22^{\text {nd }}$, 2010, the ministry of Treasury Mr. Tremonti declared: "con la cultura non si mangia" (you cannot eat culture), while Mr. Berlusconi stated that in Italy there are too many graduated individuals and too few artisans.
} 
representatives of different interest groups of the Italian society (CNEL). We demonstrate that the null of equal expenditure preference weights on different welfare domains among survey respondents is rejected by our empirical analysis since political orientation, education, gender and age significantly affect allocation choices.

More specifically on this point we show that right wing respondents desire to invest relatively more in economic wellbeing and safety, while left wing respondents in education, social relations and the environment. Overall, our findings seem to suggest that sustainable wellbeing goals may more easily achieved with left wing oriented citizens who, in a hypothetic dilemma between economic growth and environmental sustainability, are relatively more inclined toward the latter.

The impact of education is also relevant and is mainly represented by the difference made by a university degree. Graduated respondents would invest significantly more in the environment, social relations, natural and cultural heritage and quality of services.

We as well assess whether respondents' expenditure preferences on a given BES domain are affected by the relative scarcity/abundance of wellbeing on that given domain at the regional level. Our findings show the prevalence of the marginal impact hypothesis since in most cases wellbeing expenditure preferences are higher in areas where the quality of a given wellbeing domain is relatively lower.

Last but not least, the importance of the political factor (left/right wing political orientation) in between and within domain effects (and the identification of areas in which political orientation does not matter) suggests that our methodology may be used to identify areas where it is possible to form large coalitions by creating bridges and consensus between left and right political wings. 


\section{References}

Ahn, J., Lee, J., Kim, T. (2006), An Analysis of Consumer Preferences among Wireless LAN and Mobile Internet Services, ETRI Journal, 28: 205-215.

Alesina, A., Angeletos, G. M. (2005), Fairness and redistribution, American Economic Review. 95: 913-935.

Alesina, A., Glaeser, E. (2004), Fighting poverty in the US and Europe: A world of difference, Oxford: Oxford University Press.

Anand, P., Durand, M., Heckman J., (2011), The Measurement of progress -some achivements and challenges, Journal of the Royal Statistical Society A, 174:851-855

Author citation (2012), Title, Journal of Economic Geography.

Atkinson, S., Fleuret, S. (2007), Wellbeing, health and geography: A critical review and research agenda, New Zealand Geographer 63: 106-118.

Bartolini, S., Bilancini, E., Pugno, M. (2008), Did the decline in social capital decrease American happiness? A relational explanation of the happiness paradox, University of Siena Dept of Economics Working Paper 513.

Bayer, P., Ross, S. L. (2006), Identifying individual and group effects in the presence of sorting: a neighborhood effects application, NBER Working Paper 12211, National Bureau of Economic Research, Inc.

Author citation (2013a), Title, Journal of Socio-Economics.

Beggs, S., Cardell, S., Hausman, J. (1981), Assessing the Potential Demand for Electric Cars, Journal of Econometrics, 16: 1-19.

Bélanger, É., Lewis-Beck, M. S., Nadeau, R. (2013), Economics and Elections Revisited, Comparative Political Studies. 46: 551-573.

Bénabou, R. (1996), Heterogeneity, Stratification, and Growth: Macroeconomic Implications of Community Structure and School Finance, The American Economic Review, 86: 584-609.

Bruni, L., Stanca, L. (2008), Watching alone: Relational Goods, Television and Happiness, Journal of Economic Behavior and Organization, 65: 506-528.

Calfee, J., Winston, C., Stempski, R. (2001), Econometric Issues in Estimating Consumer Preferences From Stated Preference Data: A Case Study of the Value of Automobile Travel Time, The Review of Economics and Statistics , 83: 699-707.

Campbell, R. (2004) Gender, Ideology and Issue Preference: Is There such a Thing as a Political Women's Interest in Britain?, The British Journal of Politics \& International Relations, 6: 22-44.

Carson, R., Flores, N., Meade, N. (2001), Contingent valuation: controversies and evidence, Environmental and Resource Economics, 19: 173-210. 
Clark, G. L. (2015), Behaviour Cognition and Context, The New Oxford Economic Geography, Forthcoming.

Author citation (2013b), Title, Regional Studies.

Author citation (2015), Title, Journal of Economic Geography.

Croson, R., Gneezy, U. (2009), Gender Differences in Preferences, Journal of Economic Literature 4: 448-474.

Deming WE. (1943). Statistical Adjustment of Data. New York: Wiley.

De Silva, D., Pownall, R. A. J. (2012), Going green: does it depend on education, gender, or income?, MPRA Paper 36465.

Easterlin, R. A., Angelescu, L. (2009), Happiness and growth the world over: Time series evidence on the happiness-income paradox, IZA Discussion Paper 4060.

Ferrer-i-Carbonell, A. (2005), Income and well-being: an empirical analysis of the comparison income effect, Journal of Public Economics, 89: 997-1019.

Gubrium, J. F. (2000), Deconstructing Self and Well-being in Later Life, in K. W. Schaie and J. Hendricks The Evolution of the Aging Self: The Societal Impact on the Aging Process, New York, NY: Springer

Gui, B. (2005), From transactions to encounters. The joint generation of relational goods and conventional values, in Gui, B., Sugden, R. (2005), Economics and Social Interaction: Accounting for Interpersonal Relations, Cambridge: Cambridge University Press.

Helliwell, J. F., Barrington-Leigh, C. P. (2010), Measuring and Understanding Subjective Well-Being, Canadian Journal of Economics, 43 : 729-753.

Istat, (2012). Le opinioni dei cittadini sulle misure del benessere, Risultati della consultazione online." http://www.misuredelbenessere.it/fileadmin/relazionequestionarioBES.pdf

Izrael, D., Battaglia, M.P., Frankel, M.P. (2009), Extreme Survey Weight Adjustment as a Component of Sample Balancing (a.k.a. Raking) SAS Global Forum 2009, Statistics and Data Analysis.

Jiang, S., Lu, M., Sato, H. (2009), Happiness in the dual society of urban China: Hukou identity, horizontal inequality and heterogeneous reference, Global COE Hi-Stat Discussion Paper Series 20.

Kahneman D, Krueger, A. B. (2006), Developments in the Measurement of Subjective Well-Being, The Journal of Economic Perspectives, 20: 3-24.

Kalton G. (1983). Compensating for Missing Survey Data. Survey Research Center, Institute for Social Research, University of Michigan.

Kockelman, K., Podgorski, K., Bina, M., Gadda, S. (2006), Public Perceptions of Pricing Existing Roads and Other Transportation Policies: The Texas Perspective, working paper, URL: http://www.ce.utexas.edu/prof/kockelman/. 
Koop, G., Poirier, D. (1994), Rank-Ordered Logit Models: an Empirical Analysis of Ontario Voter Preferences, Journal of Applied Econometrics , 9: 369-388.

Kuhn, A. (2011), Inequality Perceptions, Distributional Norms, and Redistributive Preferences in East and West Germany, German economic review, 14: 483-499.

Liberini, F., Redoano, M., Proto, E. (2014), Happy Voters, CESifo Working Paper Series No. 5002.

Mark, D., Lusk, J., Scott Daniel, M. (2004), Recruiting Agricultural Economics Graduate Students: Student Demand for Program Attributes, American Journal of Agricultural Economics, 86: 175-184.

Moffitt, R. A. (2001), Policy interventions, low-level equilibria and social interactions, in S.N. Durlauf, H.P. Young (eds) Social Dynamics, Cambridge, MA: The MIT Press.

Mundlak, Y. (1978), On the pooling of time series and cross section data, Econometrica, 46: 69-85.

OECD, (2013), OECD Regional Well-Being: A User's Guide, www.oecdregionalwellbeing.org. Using Data to Build Better Communities.

OECD, (2014), Measuring Well-being and Progress in Countries at Different Stages of Development Towards a More Universal Conceptual Framework. OECD Publishing N. 325. Paris.

Oswald, A. J., Powdthavee, N. (2010), Daughters and Left-Wing Voting, The Review of Economics and Statistics, 92: 213-227.

Oswald, A. J., Wu, S. (2010), Objective confirmation of subjective measures of human well-being: evidence from the U.S.A., Science, 37: 576-579.

Psycharis, Y., Rodriguez-Pose A., Tselios, V. (2015), Politics and investment: examining the territorial allocation of public investment in Greece, London, Centre for Economic Policy Research.

Rampichini, C., D'Andrea, S. (1997), A hierarchical ordinal probit model for the analysis of life satisfaction in Italy, Social Indicators Research, 44: 41-69.

Schyns, P. (2002), Wealth of nations, individual income and life satisfaction in 42 countries: a multilevel approach, Social Indicators Research, 60: 5-40.

Sen, A. K. (1985), Commodities and Capabilities, Amsterdam: North-Holland.

Senik, C. (2004), Relativizing relative income, DELTA Working Paper 2004-17.

Simon, H. A. (1956), Rational choice and the structure of the environment, Psychology Review, 63: 129-38.

Sointu, E. (2005), The Rise of An Ideal: Tracing Changing Discourses of Wellbeing, The Sociological Review 53: 255-274.

Stiglitz, J. E., Sen, A. K., Fitoussi, J. P. (2012), Report by the Commission on the Measurement of Economic Performance and Social Progress. Downloadable at http:// www.stiglitz-sen-fitoussi.fr/documents/rapport anglais.pdf. 
Sugden, R. (2008), Capability, Happiness, and Opportunity, in Bruni, L., Comim, F., Pugno, M. (2008), Capabilities and Happiness, Oxford: Oxford University Press.

Uhlaner, C. J. (1989), Relational Goods and Participation: Incorporating Sociability into a Theory of Rational Action, Public Choice Journal, 62: 253-285.

Van Ophem, H., Stam, P., Van Praag, B. (1999), Multichoice Logit: Modeling Incomplete Preference Rankings of Classical Concerts, Journal of Business \& Economic Statistics, 17:117-128.

Wooldridge, J. (2002), Econometric Analysis of Cross Section and Panel Data.

Cambridge, MA: MIT Press. 


\section{Figures}

Figure 1. Regional (objective) BES composite indices.
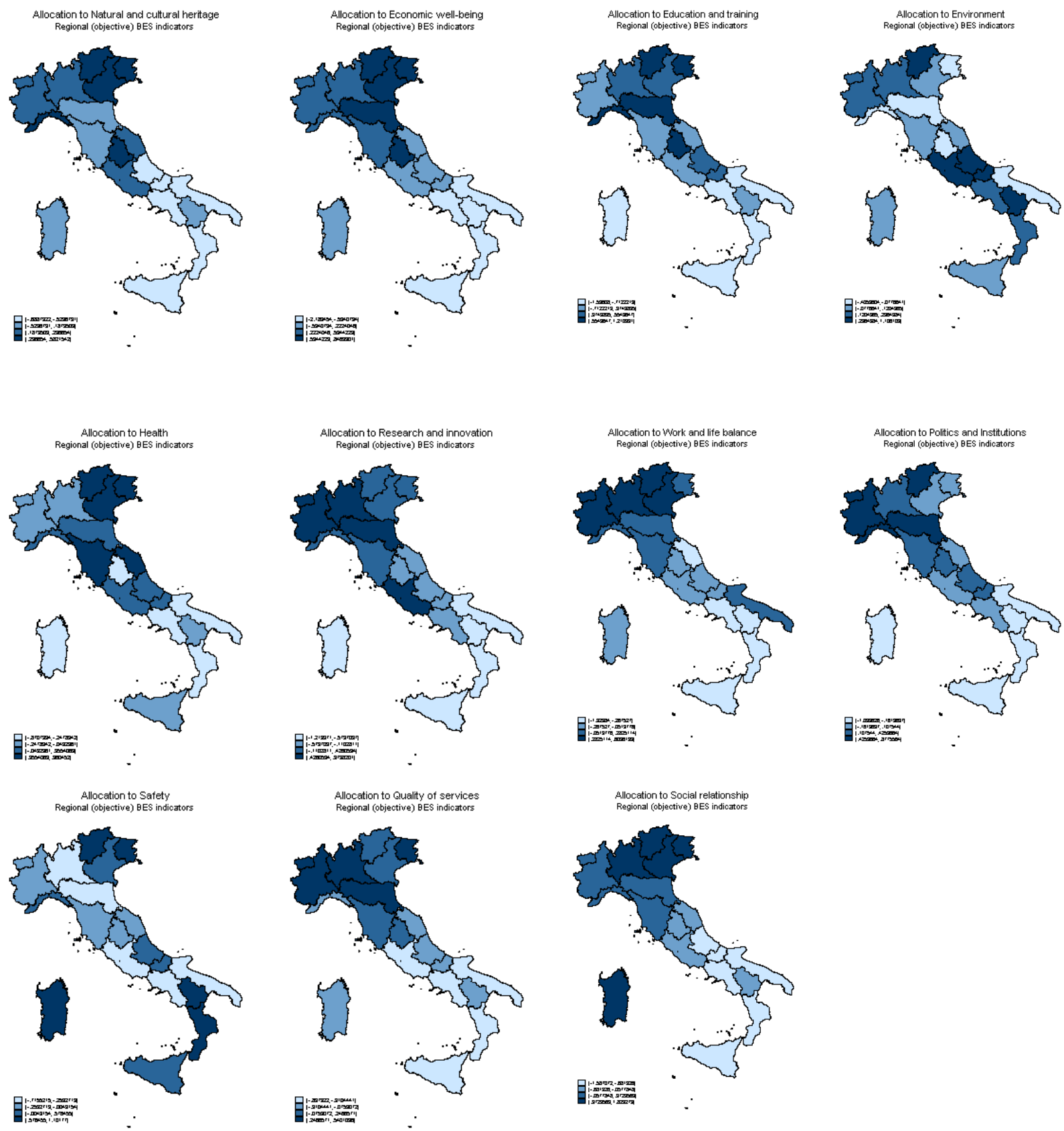
Figure 2. Average investment shares (preference weights) in the different BES domains (weighted)

Legend= Health=health, Education=education and training; Job=work and life balance; Social=social relationships; Politics=politics and institutions; Culture=natural and cultural heritage; Environment=environment; Security=safety; Innovation=research and innovation; Services $=$ quality of services

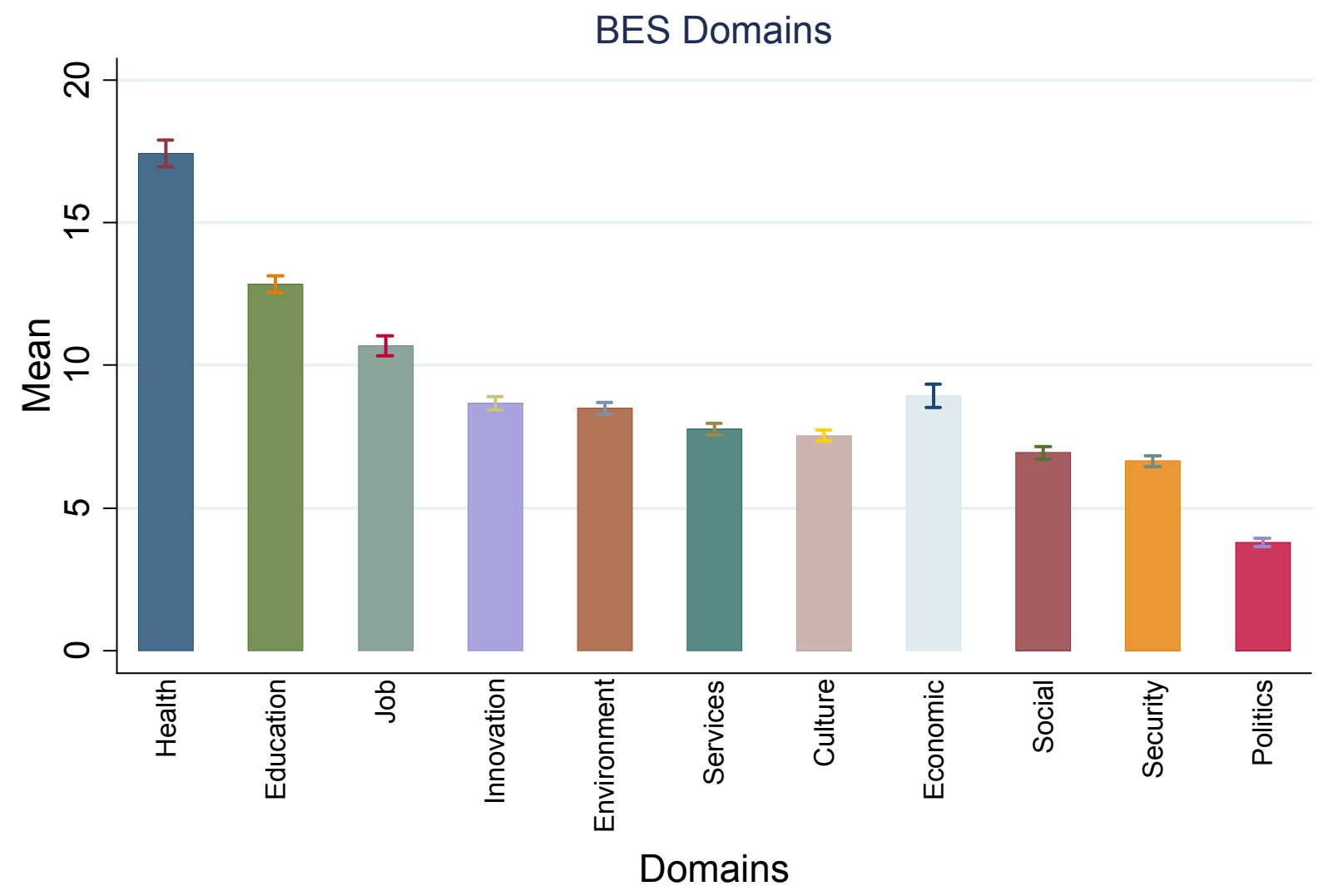

95\% Confidence interval 
Figure 3. Average investment shares in the different BES domains (weighted)

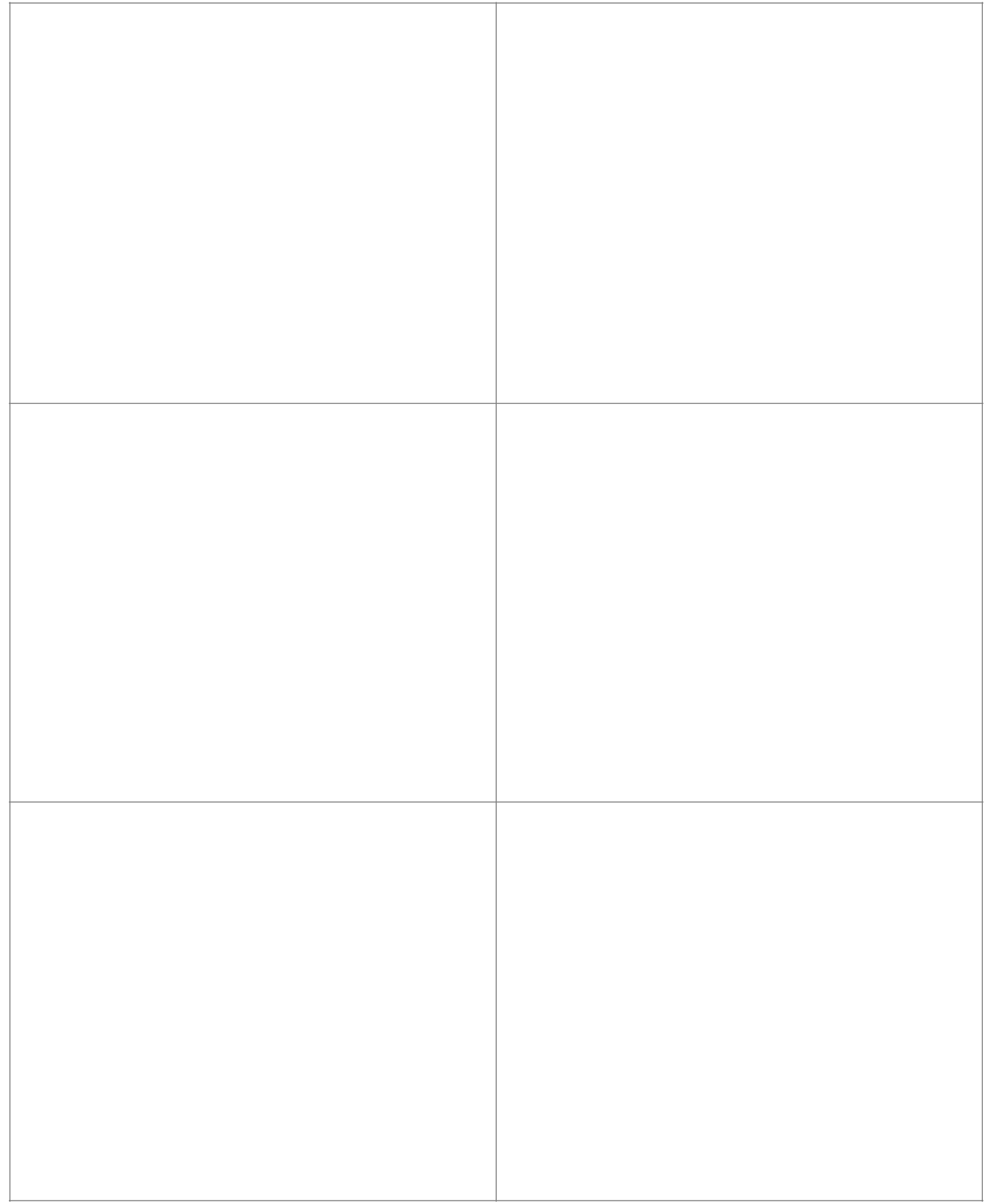

Figure 4. Regional (subjective) allocations to the BES domains (weighted) 

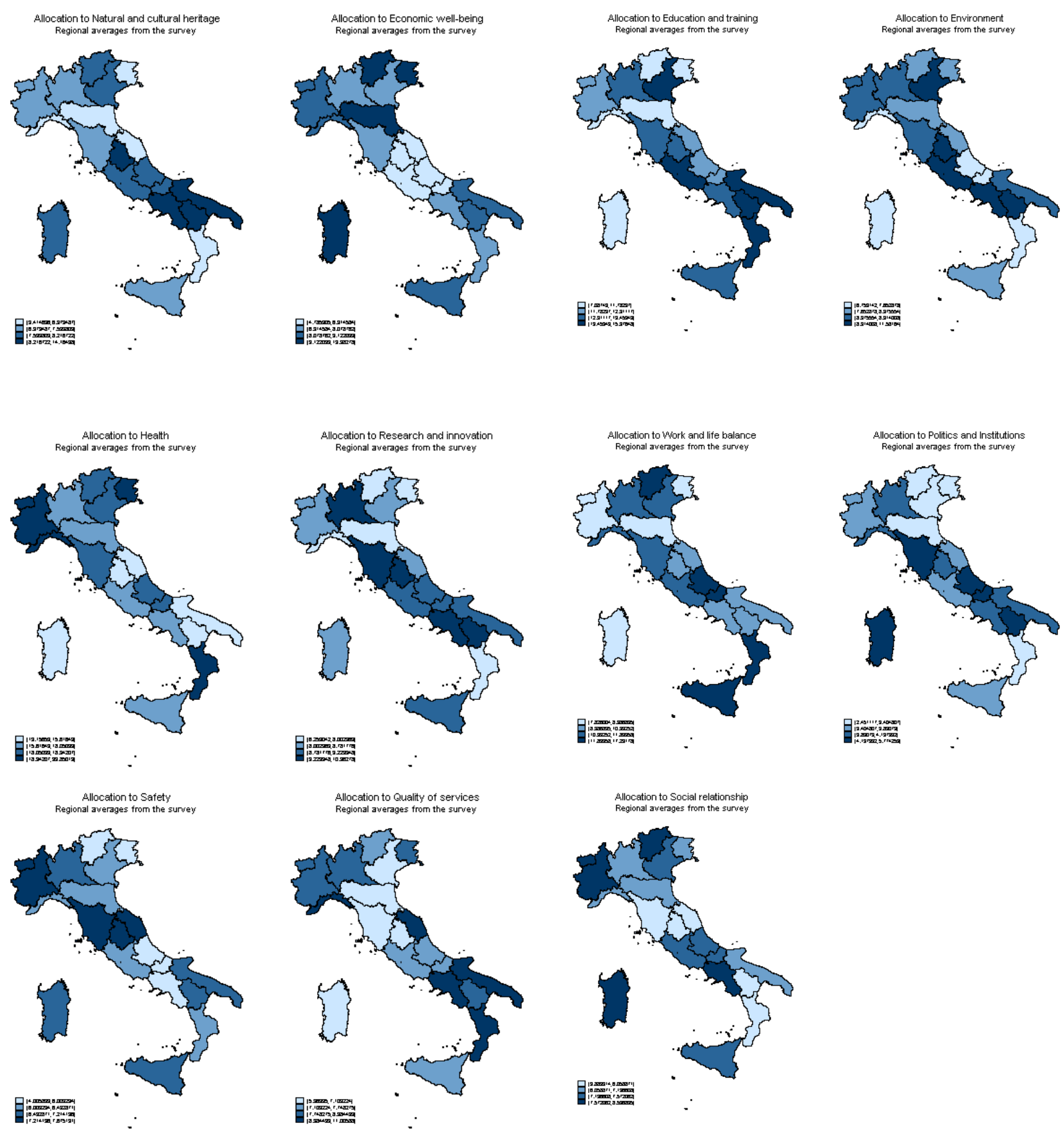
Tables

Table 1 - BES Domains and BES Regional Indicators 
Life expectancy at birth, Healthy life expectancy at birth, Physical Component Summary (PCS), Mental Component Summary (MCS), Infant mortality rate, Traffic accidents (15-34 years old), Age-standardised cancer mortality rate (19-64 years old), Age-standardised mortality rate for dementia and related Health illnesses (people aged 65 and over), Life expectancy without activity limitations at 65 years of age, Age-standardized overweight or obesity - percentage of people aged 18 years and over who are overweight or obese,Age standardized smoking - people aged 14 years and over declaring to smoke, Age-standardized alcohol consumption - people aged 14 years and over with at least one risk behaviour in alcohol consumption, Age - standardized sedentariness - people aged 14 years and over who do not practice any physical activity, Age - standardized nutrition - people aged 3 years and over who consume at least 4 portions of fruit and vegetables a day

Economic well-being

Per capita adjusted disposable income, Disposable income inequality, People at risk of relative poverty, Severely materially deprived people, People suffering poor housing conditions, People living in jobless households.

Participation in early childhood education, Percentage of people aged 25-64 having completed at least upper secondary education, Percentage of people aged 30-34 having completed tertiary education (ISCED $5 \circ 6$ ), Percentage of early leavers (aged 18-24) from education and training, Percentage of

Education people aged 15-29 not in education, employment, or training (NEET), Percentage of people aged 25-64 and Training participating in formal or non-formal education, Level of literacy: Scores obtained in the tests of functional literacy skills of students in the II classes of upper secondary education, Level of numeracy, Percentage of people aged 16 and over with high level of ICT competencies, Synthetic indicator of the level of cultural participation

Work and life balance

Social relationships

Politics and
Institutions

Institutions
Security

Homicide rate, Burglary rate, Pick-pocketing rate, Robbery rate, Physical violence rate, Sexual violence rate, Intimate partnership violence rate.

(12 months time-distance) from nonstandard to standard employment, Share of employed persons with temporary jobs for at least 5 years, Share of employees with below $2 / 3$ of median hourly earning, Share of over-qualified employed persons, Incidence rate of fatal occupational injuries or injuries leading to permanent disability, Share of employed persons not in regular occupation, Ratio of employment rate for women 25-49 years with children under compulsory school age to the employment rate of women 25-49 years without children, Share of population aged 15-64 years that work over 60 hours per week (including paid work and household work), Share of employed persons who feel satisfied with their work

Synthetic indicator of social participation, Generalized trust, Non-profit organizations per 10,000 inhabitants, Social co-operatives per 10,000 inhabitants, Volunteer work, Provided aids, Association funding, Satisfaction with family relationship, Satisfaction with friendship relationship, Percentage of people of 14 years and over which have relatives, friends or neighbours on which they can count, Percentage of children aged 3 to 10 years who play with their parents.

Voter turnout, Civic and political participation, Trust in the parliament, Trust in judicial system, Trust in political parties, Trust in local institutions, Trust in other institutions, Women and political representation in Parliament, Women and political representation at regional level, Women in decisionmaking bodies.

Endowment of cultural heritage items, Current expenditure of Municipalities for the management of cultural heritage (museums, libraries and art galleries), per capita, Illegal building rate, Urbanisation rate of areas subject to building restrictions by virtue of the Italian laws on landscape protection,

Natural and cultural heritage Erosion of farmland from urban sprawl, Erosion of farmland from abandonment, Presence of historic rural landscapes, Quality assessment of Regional programmes for rural development (PSRs), with regard to the landscape protection, Presence of Historic Parks/Gardens and other Urban Parks recognised of significant public interest, Conservation of historic urban fabric, People that are not satisfied with the quality of landscape of the place where they live, Concern about landscape deterioration

\section{Environment}

Drinkable water, Quality of marine coastal waters, Quality of urban air, Urban parks and gardens, Areas with hydrogeological risks, Contaminated sites, Terrestrial parks, Marine protected areas, Areas of special naturalistic interest, Concern for biodiversity loss, Energy from renewable sources, Emissions of $\mathrm{CO} 2$ and other greenhouse gasses.

Research and Research intensity, Patent propensity, Percentage of knowledge workers on total employment, Innovation rate of the national productive system, Percentage of product innovators, Productive specialization in high-tech and knowledge intensive sectors, Internet use. 
Index of accessibility to hospitals with emergency room, Beds in residential health care facilities,

Waiting lists, Percentage of population served by natural gas, Separate collection of municipal waste,

Quality of Composite index of service accessibility, Index of accessibility to transport networks, Citizens who

Services benefit from infancy services, Elders who benefit from home assistance, Prison density per 100 places, Irregularity in water supply, Landfill of waste, Irregularity in electric power distribution, Time devoted to mobility. 
Table 2 - Sample versus Census Population 


\begin{tabular}{|c|c|c|c|}
\hline Variable & Paper sample & Census & Z-score ${ }^{\S}$ \\
\hline \multicolumn{4}{|l|}{ Gender (\%) } \\
\hline Male & 44.45 & 48.37 & $-3.98^{* * *}$ \\
\hline Female & 55.55 & 51.63 & $3.98^{* * *}$ \\
\hline \multicolumn{4}{|l|}{ Age (\%) } \\
\hline Jan-17 & 0.12 & 16.84 & $-22.69^{* * *}$ \\
\hline $18-24$ & 3.8 & 7.13 & $-6.57^{* * *}$ \\
\hline $25-34$ & 22 & 11.87 & $15.89^{* * *}$ \\
\hline $35-44$ & 22.65 & 15.75 & $9.62^{* * *}$ \\
\hline $45-54$ & 24.61 & 15.01 & $13.65^{* * *}$ \\
\hline $55-64$ & 14.93 & 12.56 & $3.63^{* * *}$ \\
\hline Over 64 & 11.9 & 20.84 & $-11.17^{* * *}$ \\
\hline \multicolumn{4}{|l|}{ Education } \\
\hline No titles & 1.38 & 8.77 & $-13.26^{* * *}$ \\
\hline Primary school & 0.31 & 20.10 & $-25.07^{* * *}$ \\
\hline Middle school & 6.56 & 29.77 & $-25.77^{* * *}$ \\
\hline High school & 34.05 & 30.57 & $3.84^{* * *}$ \\
\hline BA or higher & 57.70 & 10.80 & $76.70^{* * *}$ \\
\hline \multicolumn{4}{|l|}{ Region } \\
\hline Abruzzo e Molise & 3.3 & 2.72 & $1.80^{*}$ \\
\hline Basilicata & 0.74 & 0.97 & -1.20 \\
\hline Calabria & 3.61 & 3.28 & 0.93 \\
\hline Campania & 1.44 & 9.69 & $-14.16^{* * *}$ \\
\hline Emilia Romagna & 16.80 & 7.30 & $18.53^{* * *}$ \\
\hline Friuli Venezia Giulia & 3.96 & 2.05 & $6.85^{* * *}$ \\
\hline Lazio & 3.84 & 9.32 & $-9.57^{* * *}$ \\
\hline Liguria & 2.48 & 2.65 & -0.53 \\
\hline Lombardia & 10.32 & 16.36 & $-8.30^{* * *}$ \\
\hline
\end{tabular}




\begin{tabular}{r|ccc} 
Marche & 2.56 & 2.59 & -0.09 \\
Piemonte e Valle D'Aosta & 6.01 & 7.54 & -2.93 \\
Puglia & 4.89 & 6.80 & -3.85 \\
Sardegna & 7.49 & 2.76 & $14.67^{* * *}$ \\
Sicilia & 10.20 & 8.40 & $3.29^{* * *}$ \\
Toscana & 12.88 & 6.17 & $14.15^{* * *}$ \\
Trentino Alto Adige & 0.58 & 1.73 & $-4.48^{* * *}$ \\
Umbria & 3.14 & 1.49 & $6.93^{* * *}$ \\
Veneto & 5.78 & 8.17 & $-4.43^{* * *}$ \\
\hline
\end{tabular}

5 * significant at $10 \%{ }^{* *}$ significant at $5 \%{ }^{* * *}$ significant at $1 \%$. Z-score $=$ where p=sample proportion,

\section{Table 3 - Summary statistics (weighted)}

\begin{tabular}{|c|c|c|c|c|c|}
\hline Variable & Obs & Mean & $\begin{array}{l}\text { Std. } \\
\text { Dev. }\end{array}$ & Min & Max \\
\hline \multicolumn{6}{|l|}{ BES DOMAINS } \\
\hline Education & 2578 & 13.59 & 6.89 & 0 & 100 \\
\hline Work and life balance & 2578 & 10.60 & 7.70 & 0 & 100 \\
\hline Economic well-being & 2578 & 7.84 & 8.21 & 0 & 100 \\
\hline Social relationship & 2578 & 6.98 & 5.04 & 0 & 44 \\
\hline Politic and Insitutions & 2578 & 3.88 & 3.97 & 0 & 100 \\
\hline Environment & 2578 & 8.81 & 4.87 & 0 & 50 \\
\hline Health & 2578 & 16.12 & 9.63 & 0 & 100 \\
\hline Safety & 2578 & 6.60 & 4.93 & 0 & 100 \\
\hline Natural and cultural heritage & 2578 & 8.01 & 4.60 & 0 & 50 \\
\hline Services quality & 2578 & 8.15 & 5.19 & 0 & 100 \\
\hline Research and innovation & 2578 & 9.15 & 5.25 & 0 & 50 \\
\hline \multicolumn{6}{|l|}{ COMMON CONTROLS } \\
\hline Per capita GDP & 2578 & 20.33 & 4.39 & 12.79 & 26.78 \\
\hline People with up to the middle school degree & 2512 & 46.90 & 7.57 & 31.60 & 65.64 \\
\hline Voters for Senate election & 2512 & 80.57 & 5.57 & 65.26 & 87.50 \\
\hline \multicolumn{6}{|l|}{ POLITICAL ORIENTATION } \\
\hline Political orientation & 2578 & -2.70 & 4.66 & -10 & 10 \\
\hline SECTOR Dummy & & & & & \\
\hline
\end{tabular}




\begin{tabular}{|c|c|c|c|c|c|}
\hline Manufacturing & 2578 & 0.13 & 0.34 & 0 & 1 \\
\hline Agriculture & 2578 & 0.02 & 0.14 & 0 & 1 \\
\hline Tertiary & 2578 & 0.49 & 0.50 & 0 & 1 \\
\hline Personal services & 2578 & 0.30 & 0.46 & 0 & 1 \\
\hline doesn't know/answer & 2578 & 0.06 & 0.23 & 0 & 1 \\
\hline \multicolumn{6}{|l|}{ CIVIL STATUS Dummy } \\
\hline Married/cohabitant & 2578 & 0.56 & 0.50 & 0 & 1 \\
\hline Single & 2578 & 0.36 & 0.48 & 0 & 1 \\
\hline Separated & 2578 & 0.04 & 0.19 & 0 & 1 \\
\hline Divorced & 2578 & 0.02 & 0.15 & 0 & 1 \\
\hline Widower & 2578 & 0.01 & 0.11 & 0 & 1 \\
\hline \multicolumn{6}{|l|}{ WORK STATUS Dummy } \\
\hline Fixed term contract & 2572 & 0.44 & 0.50 & 0 & 1 \\
\hline Open-ended and seasonal contract & 2572 & 0.11 & 0.31 & 0 & 1 \\
\hline Independent contractor/freelancer & 2572 & 0.16 & 0.37 & 0 & 1 \\
\hline Not working/unemployed/looking for a job & 2572 & 0.12 & 0.32 & 0 & 1 \\
\hline Redundancy fund benefits & 2572 & 0.00 & 0.07 & 0 & 1 \\
\hline Redundancy worker & 2572 & 0.01 & 0.09 & 0 & 1 \\
\hline Housewife & 2572 & 0.01 & 0.12 & 0 & 1 \\
\hline Student & 2572 & 0.04 & 0.20 & 0 & 1 \\
\hline Retired & 2572 & 0.10 & 0.30 & 0 & 1 \\
\hline \multicolumn{6}{|l|}{ FAMILY STATUS Dummy } \\
\hline Living alone & 2578 & 0.17 & 0.37 & 0 & 1 \\
\hline Living with my original family & 2578 & 0.20 & 0.40 & 0 & 1 \\
\hline Living with my partner without children & 2578 & 0.18 & 0.38 & 0 & 1 \\
\hline Living with my partner with children & 2578 & 0.42 & 0.49 & 0 & 1 \\
\hline I am the only parent of child/children & 2578 & 0.04 & 0.19 & 0 & 1 \\
\hline \multicolumn{6}{|l|}{ INCOME STATUS Dummy } \\
\hline Income less than $€ 15.000$ per year & 2578 & 0.25 & 0.43 & 0 & 1 \\
\hline $\begin{array}{l}\text { Income between } € 15.000 \text { and } € 30.000 \text { per } \\
\text { year }\end{array}$ & 2578 & 0.37 & 0.48 & 0 & 1 \\
\hline $\begin{array}{l}\text { Income between } € 30.000 \text { and } € 50.000 \text { per } \\
\text { year }\end{array}$ & 2578 & 0.21 & 0.40 & 0 & 1 \\
\hline $\begin{array}{l}\text { Income between } € 50.000 \text { and } € 100.000 \text { per } \\
\text { year }\end{array}$ & 2578 & 0.08 & 0.27 & 0 & 1 \\
\hline Income higher than $€ 100.000$ per year & 2578 & 0.01 & 0.10 & 0 & 1 \\
\hline doesn't know/answer & 2578 & 0.08 & 0.27 & 0 & 1 \\
\hline
\end{tabular}


Table 4 - The determinants of investment in BES domains - OLS single equation estimates (weighted)

\begin{tabular}{|c|c|c|c|c|c|c|c|c|c|c|c|}
\hline & $\begin{array}{l}\text { Educatio } \\
\mathrm{n} \& \\
\text { training }\end{array}$ & $\begin{array}{l}\text { Work \& } \\
\text { life } \\
\text { balance }\end{array}$ & $\begin{array}{l}\text { Economi } \\
\mathrm{c} \\
\text { wellbein } \\
\mathrm{g}\end{array}$ & $\begin{array}{l}\text { Social } \\
\text { relation } \\
\mathrm{s}\end{array}$ & $\begin{array}{l}\text { Politics \& } \\
\text { institutio } \\
\text { ns }\end{array}$ & $\begin{array}{l}\text { Environme } \\
\text { nt }\end{array}$ & Health & $\begin{array}{l}\text { Securit } \\
y\end{array}$ & $\begin{array}{l}\text { Quality } \\
\text { of } \\
\text { service }\end{array}$ & $\begin{array}{l}\text { Natural } \\
\text { \& } \\
\text { cult. He } \\
\text { r. }\end{array}$ & $\begin{array}{l}\text { Researc } \\
\mathrm{h} \& \\
\text { innov. }\end{array}$ \\
\hline Gender & -1.16 & -1.08 & 1.31 & 0.62 & 0.01 & 0.29 & 0.47 & 0.24 & -0.37 & -0.11 & 0.01 \\
\hline $\begin{array}{l}\text { Education } \\
\text { (middle) }\end{array}$ & $-1.29^{*}$ & 0.36 & 1.11 & 0.62 & -0.02 & -0.63 & 2.28 & -0.54 & 0.04 & -0.73 & $\begin{array}{l}-1.79^{* *} \\
*\end{array}$ \\
\hline $\begin{array}{l}\text { Education } \\
\text { (bachelor) }\end{array}$ & -0.10 & -0.53 & -0.12 & $1.52^{* * *}$ & 0.07 & 0.50 & -1.33 & -0.59 & 0.65 & 0.51 & 0.11 \\
\hline Pol. Orientation & $-0.10^{*}$ & -0.03 & $0.27^{* *}$ & $-0.11^{*}$ & -0.04 & $-0.14^{* * *}$ & 0.08 & $\begin{array}{l}0.16^{* *} \\
*\end{array}$ & 0.01 & $\begin{array}{l}-0.10^{*} \\
*\end{array}$ & -0.00 \\
\hline NorthEast & -1.97 & -0.36 & 3.87 & 1.34 & -0.74 & -0.46 & 2.66 & -0.96 & 0.69 & -1.16 & $-1.46^{*}$ \\
\hline NorthWest & -1.03 & -0.16 & -0.02 & 0.41 & 0.10 & -0.69 & $3.46^{* *}$ & 0.15 & $2.16^{* *}$ & -0.26 & -0.88 \\
\hline South-Islands & -3.63 & 1.00 & $8.84^{*}$ & 1.60 & -0.40 & -0.51 & -3.68 & -0.30 & 0.37 & -0.13 & -1.88 \\
\hline Source - Avvenire & 0.70 & 0.52 & -1.12 & -0.79 & 0.25 & -0.16 & -0.19 & 0.27 & 0.28 & $1.07^{* *}$ & -0.58 \\
\hline $\begin{array}{l}\text { Source - } \\
\text { Messaggero }\end{array}$ & $5.70^{* *}$ & $-2.57^{*}$ & -2.09 & $-3.06^{* *}$ & -1.14 & -0.34 & 2.15 & -0.02 & -1.55 & $3.48^{*}$ & -0.02 \\
\hline Source - Unità & 0.14 & 1.17 & -1.04 & -0.91 & $1.63^{* *}$ & 0.67 & $-5.81^{* *}$ & 0.65 & 0.49 & 0.97 & 1.75 \\
\hline AGE (Classes) & $\checkmark$ & $\checkmark$ & $\checkmark$ & $\checkmark$ & $\checkmark$ & $\checkmark$ & $\checkmark$ & $\checkmark$ & $\checkmark$ & $\checkmark$ & $\checkmark$ \\
\hline SECTOR & $\checkmark$ & $\checkmark$ & $\checkmark$ & $\checkmark$ & $\checkmark$ & $\checkmark$ & $\checkmark$ & $\checkmark$ & $\checkmark$ & $\checkmark$ & $\checkmark$ \\
\hline CIVIL STATUS & $\checkmark$ & $\checkmark$ & $\checkmark$ & $\checkmark$ & $\checkmark$ & $\checkmark$ & $\checkmark$ & $\checkmark$ & $\checkmark$ & $\checkmark$ & $\checkmark$ \\
\hline WORK STATUS & $\checkmark$ & $\checkmark$ & $\checkmark$ & $\checkmark$ & $\checkmark$ & $\checkmark$ & $\checkmark$ & $\checkmark$ & $\checkmark$ & $\checkmark$ & $\checkmark$ \\
\hline FAMILY STATUS & $\checkmark$ & $\checkmark$ & $\checkmark$ & $\checkmark$ & $\checkmark$ & $\checkmark$ & $\checkmark$ & $\checkmark$ & $\checkmark$ & $\checkmark$ & $\checkmark$ \\
\hline INCOME STATUS & $\checkmark$ & $\checkmark$ & $\checkmark$ & $\checkmark$ & $\checkmark$ & $\checkmark$ & $\checkmark$ & $\checkmark$ & $\checkmark$ & $\checkmark$ & $\checkmark$ \\
\hline $\begin{array}{l}\text { Common } \\
\text { controls }\end{array}$ & $\checkmark$ & $\checkmark$ & $\checkmark$ & $\checkmark$ & $\checkmark$ & $\checkmark$ & $\checkmark$ & $\checkmark$ & $\checkmark$ & $\checkmark$ & $\checkmark$ \\
\hline Constant & $18.91^{* *}$ & -22.23 & -4.12 & 6.84 & 5.35 & $13.90^{*}$ & $33.58^{*}$ & $\begin{array}{l}10.00^{*} \\
*\end{array}$ & 3.56 & 7.17 & $14.03^{* *}$ \\
\hline R-squared & 0.14 & 0.10 & 0.20 & 0.12 & 0.09 & 0.10 & 0.13 & 0.13 & 0.10 & 0.11 & 0.12 \\
\hline
\end{tabular}

${ }^{*} p<0.10{ }^{* *} p<0.05{ }^{* * *} p<0.010$ 
Table 5 - The determinants of investment in BES domains - Tobit system equation estimates (weighted)

\begin{tabular}{|c|c|c|c|c|c|c|c|c|c|c|c|}
\hline & $\begin{array}{l}\text { Educati } \\
\text { on \& } \\
\text { training }\end{array}$ & $\begin{array}{l}\text { Work \& } \\
\text { life } \\
\text { balance }\end{array}$ & $\begin{array}{l}\text { Econom } \\
\text { ic } \\
\text { wellbei } \\
\text { ng }\end{array}$ & $\begin{array}{l}\text { Social } \\
\text { relation } \\
\mathrm{s}\end{array}$ & $\begin{array}{l}\text { Politics } \\
\text { \& } \\
\text { instituti } \\
\text { ons }\end{array}$ & $\begin{array}{l}\text { Environ } \\
\text { ment }\end{array}$ & Health & Security & $\begin{array}{l}\text { Quality } \\
\text { of } \\
\text { service }\end{array}$ & $\begin{array}{l}\text { Natural } \\
\text { \& cultur. } \\
\text { Herit. }\end{array}$ & $\begin{array}{l}\text { Researc } \\
\mathrm{h} \& \\
\text { innovati } \\
\text { on }\end{array}$ \\
\hline Gender & $\begin{array}{l}-1.22^{* *} \\
*\end{array}$ & $-1.24^{* * *}$ & $1.54^{* * *}$ & $0.81^{* * *}$ & 0.02 & 0.36 & 0.40 & 0.38 & -0.36 & -0.03 & 0.06 \\
\hline Education (middle) & $\begin{array}{l}-1.60^{* *} \\
*\end{array}$ & 0.08 & $1.00^{*}$ & 0.49 & -0.28 & $\begin{array}{l}-0.82^{* *} \\
*\end{array}$ & $2.08^{* * *}$ & $\begin{array}{l}-0.81^{* *} \\
*\end{array}$ & -0.34 & $-1.16^{* * *}$ & $\begin{array}{l}-2.37^{* *} \\
*\end{array}$ \\
\hline Education (bachelor) & -0.05 & -0.58 & -0.04 & $1.81^{* * *}$ & 0.19 & $0.61^{*}$ & $-1.35^{*}$ & -0.45 & $0.67^{*}$ & $0.62^{*}$ & 0.23 \\
\hline Pol. Orientation & $\begin{array}{l}-0.11^{* *} \\
*\end{array}$ & -0.05 & $0.32^{* * *}$ & $\begin{array}{l}-0.14^{* *} \\
*\end{array}$ & $-0.05^{* *}$ & $\begin{array}{l}-0.15^{* *} \\
*\end{array}$ & 0.07 & $0.18^{* * *}$ & 0.00 & $-0.11^{* * *}$ & -0.01 \\
\hline NorthEast & $\begin{array}{l}-2.42^{* *} \\
*\end{array}$ & -0.88 & $4.52^{* * *}$ & $1.49^{* * *}$ & $\begin{array}{l}-1.01^{* *} \\
*\end{array}$ & -0.61 & $2.43^{* * *}$ & $\begin{array}{l}-1.30^{* *} \\
*\end{array}$ & 0.55 & $-1.58^{* * *}$ & $\begin{array}{l}-1.82^{* *} \\
*\end{array}$ \\
\hline NorthWest & $-1.10^{* *}$ & -0.26 & 0.92 & 0.47 & 0.16 & $-0.68^{*}$ & $3.98^{* * *}$ & 0.17 & $2.36^{* * *}$ & -0.36 & $-0.88^{* *}$ \\
\hline South-Islands & $\begin{array}{l}-4.14^{* *} \\
*\end{array}$ & 0.47 & $9.28^{* * *}$ & 1.37 & -1.13 & -0.93 & $-3.87^{* *}$ & -0.81 & 0.02 & -0.30 & $\begin{array}{l}-2.76^{* *} \\
*\end{array}$ \\
\hline Source - Avvenire & $0.89^{* *}$ & 0.73 & -1.06 & $-0.80^{* *}$ & 0.34 & -0.09 & -0.09 & 0.49 & 0.35 & $1.28^{* * *}$ & -0.50 \\
\hline Source - Messaggero & $6.01^{* * *}$ & -2.30 & $-3.25^{*}$ & $\begin{array}{l}-4.18^{* *} \\
*\end{array}$ & $-1.93^{* *}$ & -0.21 & 2.68 & -0.38 & $-1.75^{*}$ & $3.81^{* * *}$ & -0.12 \\
\hline Source - Unità & 0.50 & 1.68 & -0.81 & -0.79 & $2.30^{* * *}$ & 0.87 & $\begin{array}{l}-5.73^{* *} \\
*\end{array}$ & 1.09 & 0.75 & 1.37 & 1.77 \\
\hline AGE (Classes) & $\checkmark$ & $\checkmark$ & $\checkmark$ & $\checkmark$ & $\checkmark$ & $\checkmark$ & $\checkmark$ & $\checkmark$ & $\checkmark$ & $\checkmark$ & $\checkmark$ \\
\hline SECTOR & $\checkmark$ & $\checkmark$ & $\checkmark$ & $\checkmark$ & $\checkmark$ & $\checkmark$ & $\checkmark$ & $\checkmark$ & $\checkmark$ & $\checkmark$ & $\checkmark$ \\
\hline CIVIL STATUS & $\checkmark$ & $\checkmark$ & $\checkmark$ & $\checkmark$ & $\checkmark$ & $\checkmark$ & $\checkmark$ & $\checkmark$ & $\checkmark$ & $\checkmark$ & $\checkmark$ \\
\hline WORK STATUS & $\checkmark$ & $\checkmark$ & $\checkmark$ & $\checkmark$ & $\checkmark$ & $\checkmark$ & $\checkmark$ & $\checkmark$ & $\checkmark$ & $\checkmark$ & $\checkmark$ \\
\hline FAMILY STATUS & $\checkmark$ & $\checkmark$ & $\checkmark$ & $\checkmark$ & $\checkmark$ & $\checkmark$ & $\checkmark$ & $\checkmark$ & $\checkmark$ & $\checkmark$ & $\checkmark$ \\
\hline INCOME STATUS & $\checkmark$ & $\checkmark$ & $\checkmark$ & $\checkmark$ & $\checkmark$ & $\checkmark$ & $\checkmark$ & $\checkmark$ & $\checkmark$ & $\checkmark$ & $\checkmark$ \\
\hline \multicolumn{12}{|l|}{ Common controls } \\
\hline Per capita GDP & $0.30^{* * *}$ & $0.21^{*}$ & -0.03 & -0.15 & -0.07 & 0.01 & $\begin{array}{l}-0.67^{* *} \\
*\end{array}$ & 0.08 & $-0.12^{*}$ & $-0.23^{* * *}$ & -0.10 \\
\hline $\begin{array}{l}\text { Ppl wlup to mid school } \\
\text { deg. }\end{array}$ & $0.09^{* * *}$ & 0.05 & $-0.08^{*}$ & $\begin{array}{l}-0.08^{* *} \\
*\end{array}$ & 0.00 & -0.02 & $-0.09^{*}$ & $0.04^{*}$ & -0.03 & $0.04^{* *}$ & $0.10^{* * *}$ \\
\hline $\begin{array}{l}\text { Voters for Senate } \\
\text { election }\end{array}$ & $\begin{array}{l}-0.18^{* *} \\
*\end{array}$ & $0.32^{* * *}$ & $0.21^{* *}$ & 0.04 & -0.02 & -0.07 & 0.02 & $-0.09^{*}$ & 0.06 & 0.01 & $-0.11^{* *}$ \\
\hline Education - Index & $-1.93^{* *}$ & & & & & & & & & & \\
\hline $\begin{array}{l}\text { Work \& life bal. - } \\
\text { Index }\end{array}$ & & $-4.82^{* * *}$ & & & & & & & & & \\
\hline
\end{tabular}




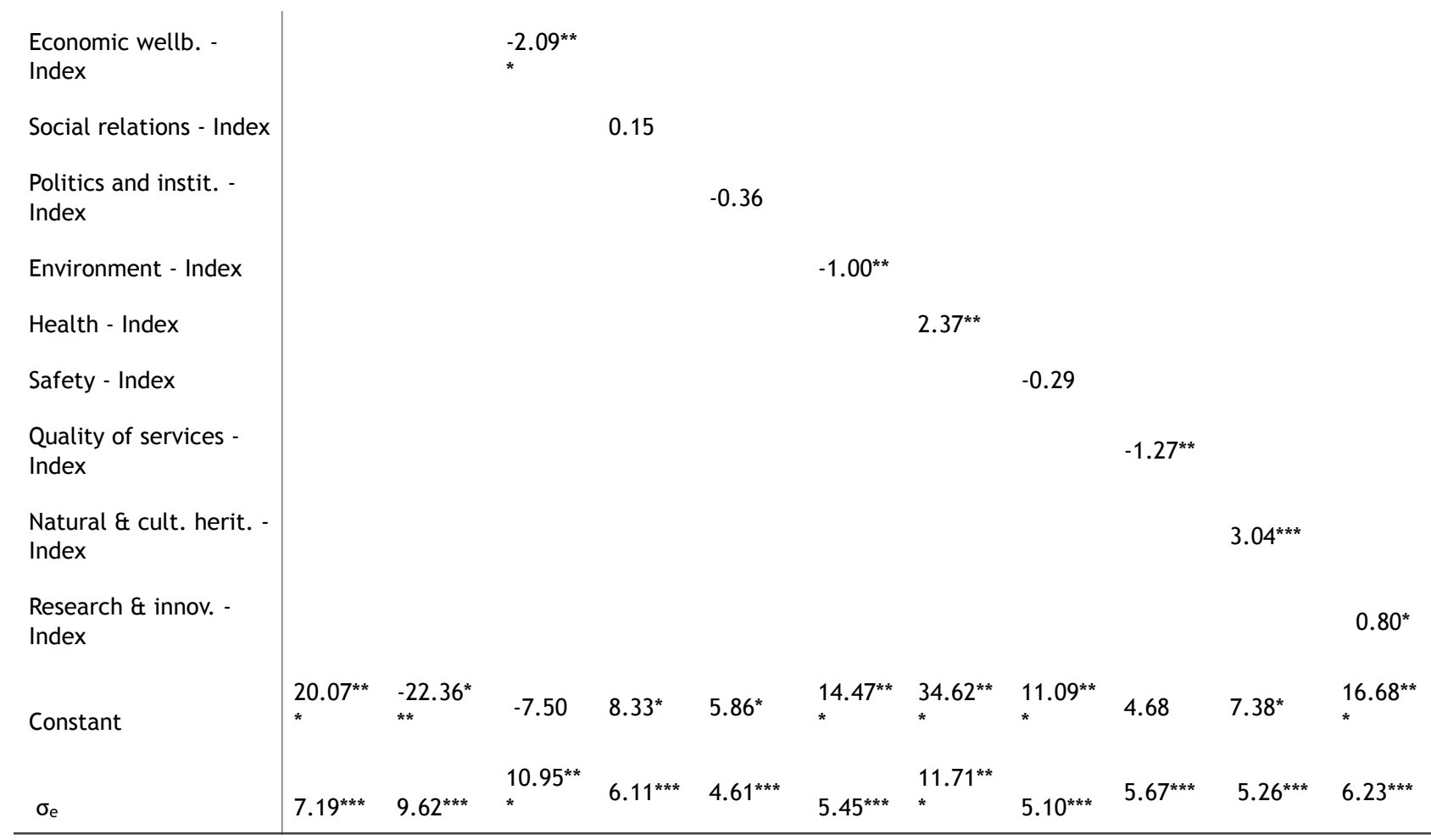

${ }^{*} p<0.10{ }^{* *} p<0.05{ }^{* * *} p<0.010$

Table 6 - Priority items according to left/right political orientation. Multinomial Logit Estimates (weighted)

\begin{tabular}{l|c|c}
\hline & Left (\%) & Right (\%) \\
\hline Health & & \\
& & \\
Cancer mortality & 16.17 & \\
Sedentariness & 3.65 & \\
Smoking & & 2.50 \\
Traffic accidents & & 1.65
\end{tabular}




\begin{tabular}{|c|c|c|}
\hline Education & & \\
\hline Level of literacy & & 13.87 \\
\hline \multicolumn{3}{|l|}{ Work and life balance } \\
\hline Underpaid workers & & 9.12 \\
\hline \multicolumn{3}{|l|}{ Economic well-being } \\
\hline Per capita net wealth & & 1.93 \\
\hline \multicolumn{3}{|l|}{ Social relations } \\
\hline Association funding & 17.37 & \\
\hline Voluntary activity & & 14.68 \\
\hline Free help provided & & 6.25 \\
\hline \multicolumn{3}{|l|}{ Politics and Institutions } \\
\hline Women in decision-making bodies & 6.32 & \\
\hline Women on boards of directors & 0.12 & \\
\hline \multicolumn{3}{|l|}{ Research and Innovation } \\
\hline Productive specialization & & 35.06 \\
\hline \multicolumn{3}{|l|}{ Quality of services } \\
\hline Composite index of service accessibility & & 26.26 \\
\hline Prison density & 16.24 & \\
\hline
\end{tabular}

Table legend: in the left (right) column we report the predicted probability of being ranked as first item among those within a given domain for indicators where left(right) political orientation significantly affects that probability. 